\title{
EL TÍTULO PRIMORDIAL TARASCO DE TÓCUARO, MICHOACÁN
}

\section{THE TARASCAN PRIMORDIAL TITLE FROM TÓCUARO, MICHOACÁN}

\author{
HANS ROSKAMP \\ CRISTINA MONZÓN
}

\begin{abstract}
RESUmen. Los títulos primordiales constituyen una importante categoría en el amplio corpus de documentos nativos de la Nueva España de los siglos XVII y xVIII. Generalmente elaborados por escribanos (carariecha) locales o especialistas regionales, quienes combinaron información tomada de documentos más antiguos y de la tradición oral, enfatizan la fundación de los pueblos y los límites de sus tierras. Estas historias locales fueron — y a menudo siguen siendo — empleadas cuando la integridad territorial de la comunidad llegó a ser amenazada por los vecinos. El presente artículo incluye la transcripción, traducción y análisis de un título primordial escrito en lengua tarasca o p'urhépecha. El documento, actualmente custodiado en la Biblioteca Nacional de Antropología e Historia en la Ciudad de México, originalmente viene de Tócuaro, un pequeño pueblo en la orilla sur del Lago de Pátzcuaro en Michoacán.
\end{abstract}

PALABRAS ClavE: Michoacán, tarascos, Colonia, títulos primordiales, tenencia de la tierra.

SummaRY. Primordial titles form an important category in the extensive corpus of native documents from 17 th and 18th century New Spain. Generally made by local scribes (carariecha) or regional specialists who combined information from older documents and oral tradition, they emphasize the foundation of the villages and the boundaries of their lands. These local histories were — and often still are — used whenever the territorial integrity of the community was threatened by their neighbors. The present article includes the transcription, translation and analysis of a primordial title written in the Tarascan or P'urhépecha language. The document, now kept in the National Library of Anthropology and History (BNAH) in Mexico City, originally comes from Tócuaro, a small village on the southern shores of Lake Pátzcuaro in Michoacán.

KEYWORDS: Michoacán, Tarascans, Colonial period, primordial titles, land tenure.

\section{Introducción}

El 16 de febrero de 1958, un habitante de Pátzcuaro llamado Gabino Ramos Estrada ofreció en venta unos documentos históricos del pueblo de Tócuaro a representantes del Museo Nacional de Antropología. ${ }^{1}$ Esta institución, ubicada en la Ciudad de México, mostró interés y apenas cuatro días después (el 20 de febrero) se concretó la transacción con un

${ }^{1}$ El vendedor poseía un predio urbano en Tócuaro y es posible que haya sido originario de esta comunidad (Periódico Oficial del Gobierno Constitucional del Estado de Michoacán de Ocampo, 27 de septiembre de 2016, 1a. Secc., p. 7). 
precio de 250 pesos, como se señala en una breve carta que todavía se conserva junto con los manuscritos antiguos. La documentación fue catalogada como "Títulos de Tócuaro" y actualmente se encuentra en la bóveda de códices de la Biblioteca Nacional de Antropología e Historia (BNAH) que comparte edificio con el museo. Una descripción de la misma (con la clave 35-116) forma parte de un importante catálogo publicado por John B. Glass en 1964. Según el investigador norteamericano se trata de títulos de tierras incompletos que consisten de 13 fojas maltratadas de papel europeo (de 31 x $21 \mathrm{~cm}$ ), de las cuales una sobrevive en forma de pequeño fragmento (Glass, 1964: 173). ${ }^{2}$

En el pequeño corpus documental se encuentra un título en lengua tarasca (fojas 11v-13r) y un "titulo trasuntado de la lengua tarasca" (fojas 9r-v), es decir una versión en lengua española, ambos sin fecha de elaboración y sin nombre de autor, en papel que carece de sellos. Existe otro ejemplar en español ("Título tracentaron de la Lengua Tarasca.") que fue publicado a principios del siglo xx por el Dr. Nicolás León (León, 1906: 405-406). ${ }^{3}$ Estos textos tratan de la fundación del pueblo en la época prehispánica y otros sucesos ocurridos en vísperas de la Conquista. Se inscriben en el género de los "títulos primordiales" que fueron elaborados principalmente en los siglos xVII-XVIII y que proporcionan una visión indígena de la historia local, enfatizando sobre todo la toma de posesión de tierras. ${ }^{4}$

Si bien la elaboración de documentos en lengua tarasca parece haber disminuido gradualmente a partir del siglo XvII (su auge fue en el siglo XVI), es probable que la presencia generalizada de los títulos primordiales hacia finales de la Colonia pueda considerarse como una recuperación significativa, aunque fuera parcial y momentánea. Son muy pocos los títulos redactados en este idioma nativo que sobrevivieron los estragos del tiempo, pero la existencia de numerosas traducciones antiguas al español muestra que la producción original fue más amplia. ${ }^{5}$ El título en lengua indígena de Tócuaro (véanse las

${ }^{2}$ Sus observaciones constituyeron la base para comentarios más breves sobre los mismos títulos en un catálogo posterior que también abarca colecciones de códices en acervos norteamericanos y europeos (Glass y Robertson, 1975: 219).

${ }^{3}$ El investigador, quien encontró el documento (cuyos rasgos físicos se desconocen) en un repositorio no identificado, era originario de Quiroga y director fundador del importante Museo Michoacano en Morelia. Tenía acceso a una amplia gama de manuscritos y libros, muchos de los cuales formaron parte de su propia biblioteca (Roskamp, 1998: 60-71 y Roskamp, 2011a).

${ }^{4}$ López Caballero (2003) presenta una discusión de la vasta bibliografía sobre el tema que incluye tanto publicaciones de textos individuales como reflexiones sobre conjuntos documentales. Para una reflexión general sobre los títulos primordiales de Michoacán, en que también se incluyen los ejemplares de Tócuaro, véase Roskamp (2010, 2016).

${ }^{5}$ A veces se señala claramente que se trata de traducciones, mientras que en otras ocasiones se omite esta información y son los elementos ortográficos, gramaticales y estilísticos que evidencian que las versiones 
figuras 1 - 4) constituye el tema del actual artículo: primero se presentan nuestra propia transcripción y traducción, para luego analizar el contenido del texto, comparando el discurso con otros títulos y sobre todo con la Relación de Michoacán (1539-1541) que contiene la información escrita más temprana y abundante sobre la cultura precolombina de la región en cuestión. ${ }^{6}$ También se incluyen referencias a los dos trasuntos, especialmente en los casos en que difieren de la versión tarasca. ${ }^{7}$

\section{Transcripción y traducción}

En nuestra versión paleográfica del texto se ha separado el continuo gráfico en palabras, tomando en consideración la estructura morfológica de la lengua. También hemos aplicado una división en diversas oraciones y párrafos, agregando nuestra propia numeración. Para resaltar algunas grafías que serán explicadas posteriormente, se usan negritas (algunas se encuentran subrayadas). Las pocas palabras tachadas aparecen de esta manera en el manuscrito original y parecen corresponder a correcciones por parte de los escribanos (carariecha). Debido a las condiciones físicas del documento, existen diversas partes que resultan difíciles de leer, mientras que la última foja (número 13) únicamente sobrevive en forma de pequeño fragmento: los elementos y secciones ilegibles se encuentran marcados con corchetes que encierran puntos suspensivos. Cabe agregar que nuestra traducción del texto es de tipo interlineal (Schultze-Berndt, 2007) y que se utiliza un sistema de cuatro renglones. Esta modificación introduce un segundo renglón con el fin de ofrecer al lector la posibilidad de controlar las decisiones tomadas en el análisis, pudiendo observar la equivalencia entre la raíz y los morfemas que se encuentran en los diccionarios y artes del siglo xvi y la redacción del propio escribano (carari) que elaboró el título.

están basadas en textos redactados en idioma tarasco. Un buen ejemplo de esta última categoría es el llamado Códice Plancarte, documento del pueblo de Carapan (León, 1990 [1888]).

6 Teniendo en cuenta el estado delicado del documento original, para nuestro estudio contamos con un microfilm (elaborado en 1994) y fotografías a color (tomadas en 2000). Una versión digitalizada de las últimas imágenes nos fue amablemente proporcionada por el Dr. Baltazar Brito Guadarrama, director de la BNAH, a quien agradecemos mucho su valioso apoyo. Son estas fotografías que se reproducen en blanco y negro al final del artículo (figuras 1 - 4), después de un procesamiento digital (a cargo de los autores) para resaltar lo mejor posible el texto y el delicado estado físico del documento.

${ }^{7}$ El trasunto inédito que forma parte del corpus de "Títulos de Tócuaro" será referido como T-BNAH, el ejemplar publicado en 1906 como T-NL. Véase la tabla 2 para facilitar la comparación de las tres versiones del título. 
Tabla 1. Sistema de análisis de texto

\begin{tabular}{|l|l|}
\hline Primer renglón & $\begin{array}{l}\text { copia del texto original, tomando decisiones sobre la secuencia fó- } \\
\text { nica que conforma la palabra }\end{array}$ \\
\hline Segundo renglón & $\begin{array}{l}\text { corte morfémico de la palabra cuya ortografía se registra en los } \\
\text { diccionarios del siglo xvI }\end{array}$ \\
\hline Tercer renglón & glosas de cada morfema \\
\hline Cuarto renglón & traducción (en este caso por cada párrafo u oración) \\
\hline
\end{tabular}

$[f .11 v]\left[\right.$ margen izquierdo] titulo [centro] Tocuaro ${ }^{8}$

\begin{tabular}{|c|c|c|c|c|}
\hline $\mathrm{yxu}$ & hatziquareca & miuantsiqua & hi & yrecha \\
\hline yxu & hatzi-quare-ca & miua-ntsi-qua & hi & yrecha \\
\hline aquí & poner-ACC.IND-1/2PAS & acordarse-CABEZ-SUST & yo & \\
\hline
\end{tabular}

$\begin{array}{llll}\text { tsiuanqua } & \text { ysqui } & \text { nah } & \text { macungaposca } \\ \text { Tsiuanqua } & \text { ysqui } & \text { nah } & \text { macu-nga-po-s-ca } \\ \text { Tsiuangua } & \text { como/que } & \text { cómo } & \text { AUX-AG.GRAL-lugares-PERF-1/2/3 }\end{array}$

habu patzangani

hamberi patza-nga-ni

pariente guardar-pecho-INF

Aqui yo, el rey Tsiuangua, de mi voluntad he puesto mi memoria ${ }^{9}$ sobre cómo en distintos lugares los parientes lo guardan en su pecho.

$\begin{array}{lllll}\text { 2. yqui } & \text { uantacungaca } & \text { yrecha } & \text { tsivaqua } & \text { ysqui } \\ \text { yqui } & \text { vanda-cu-nga-ca } & \text { yrecha } & \text { Tsiuangua } & \text { ysqui } \\ \text { entonces } & \text { hablar-BENEF.3-AG.GRAL-1/2/3 } & \text { rey } & \text { Tsiuangua } & \text { como/que }\end{array}$

$\begin{array}{llll}\text { no ambe } & \text { xucupararini } & \text { hamavaca } & \text { ysqui } \\ \text { no ambe } & \text { xucu-para-ri-ni } & \text { hama-ua-ca } & \text { ysqui } \\ \text { no cosa } & \text { arropar-ESPAL-ESTC-INF } & \text { andar-FUT-1/2/3 } & \text { como/que }\end{array}$

${ }^{8}$ El título se encuentra escrito en medio de un dibujo de dos plumas o listones verticales que descansan sobre una base: de esta manera se parece a un marco parcial.

9 Una traducción alternativa seria 'tengo en mi memoria', basada en las siguientes entradas del Diccionario Grande de la Lengua de Michoacán (1991): "Hatziquareni siruri ycaraquareni. Plantar viña para si" que permite interpretar 'poner para si', mientras que miuansqua se traduce como 'memoria', siguiendo lo indicado en la entrada "Miuansqua hatziquarepani. Yrlo poniendo en su memorial". 


\begin{tabular}{|c|c|c|c|c|c|c|c|}
\hline \multicolumn{2}{|c|}{$\begin{array}{l}\text { sicuirinco } \\
\text { sicui-ri=ni=hco } \\
\text { desollar-SUST=ENF=unifica }\end{array}$} & $\begin{array}{l}\text { ma } \\
\text { ma } \\
\text { uno }\end{array}$ & \multicolumn{2}{|c|}{$\begin{array}{l}\text { hoquarerini } \\
\text { ho-quare-ri-ni } \\
\text { atar-ACC.IND-ESTC-INF }\end{array}$} & \multicolumn{2}{|c|}{$\begin{array}{l}\text { hamavaca } \\
\text { hama-ua-ca } \\
\text { andar-FuT-1/2/3 }\end{array}$} & \\
\hline ysqui & thireuaca & auani & $\mathrm{ca}$ & axuni & $\mathrm{ca}$ & acuitze & $\mathrm{ca}$ \\
\hline ysqui & thire-ua-ca & auani & $\mathrm{ca}$ & axuni & $\mathrm{ca}$ & acuitze & $\mathrm{ca}$ \\
\hline como/que & comer-FuT-1/2/3 & conejo & $\mathrm{y}$ & venado & $\mathrm{y}$ & culebra & $\mathrm{y}$ \\
\hline
\end{tabular}

Entonces se le pidió al rey Tsiuangua que no se vistiese, que fuese únicamente un cuero lo que se amarrase [y] que comiese conejos, venados, culebras y codornices.
3. ys axamengati angaparacua ca canicuqua
ys axa-me-nga-ti anga-para-qua ca cani-cu-qua
así enviar-BENEF.PSV-AG.GRAL-3PAS erecto-ESPAL-SUST y estar.arqueado-RL-SUST

$\begin{array}{lllllll}\text { ca } & \text { tiripeti } & \text { angamequa } & \text { ca } & \text { maruvati } & \text { uegachaqua } & \text { tiripeti } \\ \text { ca } & \text { tiripeti } & \text { anga-me-qua } & \text { ca } & \text { maruua-ti } & \text { veca-hcha-qua } & \text { tiripeti } \\ \text { y } & \text { oro } & \text { erecto-LIQ-SUST } & \text { y } & \text { ser.de.valor-susT } & \text { poner-cuello-SusT } & \text { oro }\end{array}$
hucati ca xas nirahanti varaquareni thirequa hiringaquareni
huca-ti ca xas nira-ham-ti vara-quare-ni thire-qua hiringa-quare-ni
tener-3PAS y así ir-IMPF-3 cazar-ACC.IND-INF comer-SUST buscar-ACC.IND-INF
angaparaqua hucarini $^{10}$
anga-para-qua huca-ri-ni
erecto-ESPAL-SUST tener-ESTC-INF
Así se le envió un carcaj de flechas y un arco. Y él tenía puesto un bezote de oro y un collar de oro precioso. Y de este modo él iba a cazar, era comida la que buscaba con el carcaj de flechas.

[margen izquierdo] toquaro

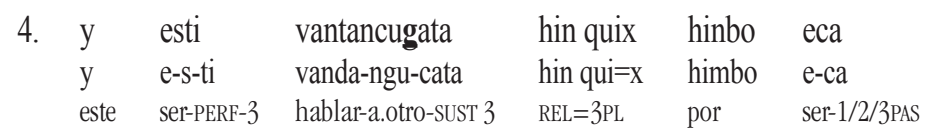

${ }^{10}$ Aquí termina la parte correspondiente al primer escribano, también claramente marcada por una línea horizontal que la separa de la siguiente sección. 


$\begin{array}{lllll}\text { tharencha } & \text { andumucha } & \text { ys } & \text { vandanuquareti } & \text { andumuti } \\ \text { thare-echa } & \text { andu-mu-echa } & \text { ys } & \text { vanda-nu-quare-ti } & \text { andu-mu-ti } \\ \text { viejo-PL } & \text { honra-boca-PL } & \text { así } & \text { hablar-atrás-ACC.IND-3PAS } & \text { honra-boca-Sust }\end{array}$

Esta es la ley por la que los ancianos son honorables, ${ }^{11}$ tal como el bonorable hizo el testamento. ${ }^{12}$

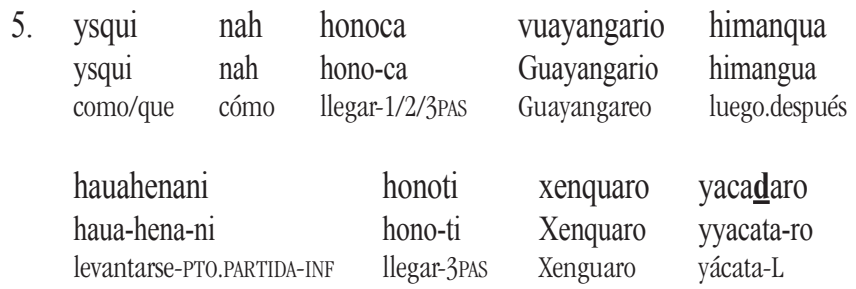

$\begin{array}{lllll}\text { hatziti } & \text { ma } & \text { phitaqua: } & \text { angaquatani }^{13} & \text { hima } \\ \text { hatzi-ti } & \text { ma } & \text { pitaqua } & \text { anga-qua-hta-ni } & \text { hima } \\ \text { poner-3PAS } & \text { una } & \text { flecha } & \text { erecto-rápidamte-PIER-INF } & \text { allá }\end{array}$

$\begin{array}{lllllll}\text { hauahenti } & \text { hononi } & \text { cutzare } & {[\ldots] \text { cata }} & \text { hinbo } & \text { hononi } & \text { himanhqua } \\ \text { haua-hena-ti } & \text { hono-ni } & \text { cutzare } & \text { yyacata } & \text { himbo } & \text { hono-ni } & \text { himangua } \\ \text { levantarse-PT0.PARTIDA-3PAS } & \text { llegar-INF } & \text { Cutzare } & \text { yácata } & \text { por } & \text { llegar-INF } & \text { luego }\end{array}$

$\begin{array}{llllll}\text { hauahenani } & \text { honoti } & \text { zintzuntzan } & \text { yacataro } & \text { ca } & \text { ys } \\ \text { haua-hena-ni } & \text { hono-ti } & \text { Zintzuntzan } & \text { yyacata-ro } & \text { ca } & \text { ys } \\ \text { levantarse-PT0.PARTIDA-INF } & \text { llegar-3PAS } & \text { Tzintzuntzan } & \text { yácata-L } & \text { y } & \text { así }\end{array}$

$\begin{array}{lllll}\text { vntadi } & \text { tarathauani } & \text { zintzuni } & \text { echani } & \text { chanarahuani } \\ \text { vnda-ti } & \text { thahra-ta-hua-ni } & \text { tzintzuni } & \text { echa-ni } & \text { chana-ra-hua-ni } \\ \text { comenzar-3PAS } & \text { levantarse.por.aire-CAUS-A.3PL-INF } & \text { colibrí } & \text { PL-A } & \text { jugar-CAUS-A.3PL-INF }\end{array}$

$\begin{array}{lllll}\text { himanqua } & \text { hauahenani } & \text { honoti } & \text { xanicho: } & \text { himanqua } \\ \text { himangua } & \text { haua-hena-ni } & \text { hono-ti } & \text { Xanich } & \text { himangua } \\ \text { luego.después } & \text { levantarse-PTO.PARTIDA-INF } & \text { llegar-3PAS } & \text { Janitzio } & \text { luego.después }\end{array}$

${ }^{11}$ El Diccionario Grande de la Lengua de Michoacán (1991) da la siguiente entrada: "Andumunstani. Tener meritos, o alcançarlos.". En el Vocabulario en lengua de Mechuacán de Gilberti (1997) encontramos "Andumunstani. merecer en algo", "Andumuni. adquirir honrras, o riquezas" y "Andumucha. los que las han adquirido.".

${ }^{12}$ El Diccionario Grande de la Lengua de Michoacán (1991) menciona "Vandanuhquareni. Hazer testamento, disponer de todas sus cosas.".

${ }^{13}$ Después de esta palabra se encuentra el dibujo de una flecha. 


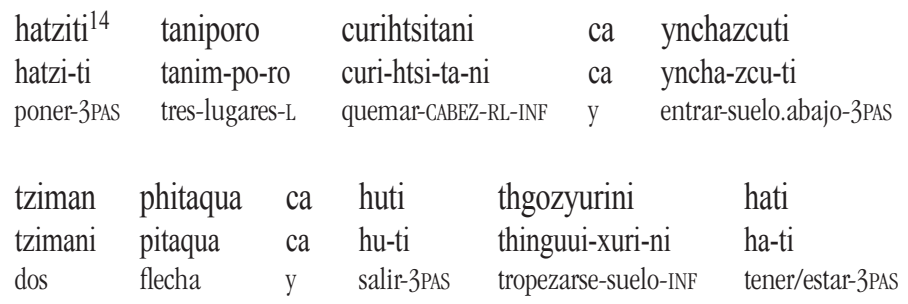

$\begin{array}{llllllll}\text { minta } & \text { hantziri } & \text { tzacabu } & \text { himbo } & \text { ca } & \text { none } & \text { exeti } & \text { ysqui } \\ \text { minda } & \text { hantziri } & \text { tzacapu } & \text { himbo } & \text { ca } & \text { none } & \text { exe-ti } & \text { ysqui } \\ \text { señal } & \text { pie } & \text { piedra } & \text { por } & \text { y } & \text { nadie } & \text { ver-3PAS } & \text { como/que }\end{array}$

nah hutamoposca

nah hu-ta-mo-po-s-ca

cómo salir-CAus-de.paso.regreso-lugares-PERF-1/2/3

Cómo [Tsiuangua] decidió llegar a Guayangareo. Luego salió de ahi y llegó a Xenguaro, al costado de las yácatas clavó una flecha. De allí salió y llegó a Cutzare, llegó a las yácatas. Luego de abípartió [y] llegó a las yácatas de Tzintzuntzan y así hizo que los colibries empezasen a volar, los hizo jugar. Luego salió de ahi [y] llegó a Xanicho, [donde] entonces puso en tres lugares que emitían llamaradas y clavó en el suelo dos flechas..$^{15}$ Al irse se tropezó, hay una piedra con una buella por señal y nadie la vio puesto que venían pasando por varios lugares.

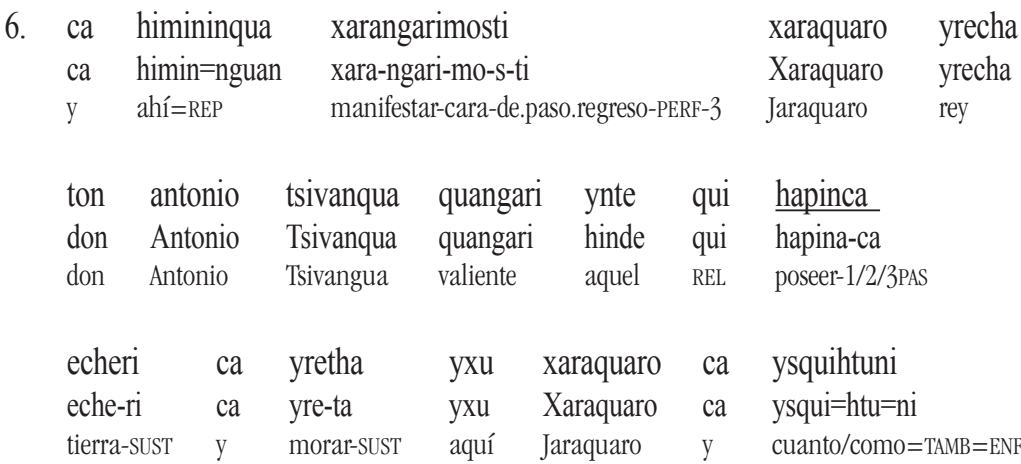

${ }^{14}$ Aparecen dos flechas paradas (con la punta hacía abajo) que atraviesan el término batziti de la siguiente forma: ha[flecha $]$ tzi[flecha $]$ ti.

${ }^{15}$ Los 'tres lugares que emitían llamaradas' probablemente se remiten a fogatas puestas por el rey antes de clavar las flechas: según el final de la oración se trataba de dos proyectiles (tziman phitaqua). Quizá las dos flechas que se encuentran dibujadas antes en la misma oración, en espacios que dejó el escribano al interior del término batziti ('puso' en español), se remiten a la misma acción. 


$\begin{array}{llllll}\text { nah } & \text { yurutzehuanstasca } & \text { ton } & \text { fran }^{\text {co: }} & \text { tsintsichani } & \text { ca } \\ \text { nah } & \text { yuru-tze-hua-nsta-s-ca } & \text { don } & \text { Francisco } & \text { Tsintsicha-ni } & \text { ca } \\ \text { cómo } & \text { escurrir-S.INF-A.3PL-CONS-PERF-1/2/3 } & \text { don } & \text { Francisco } & \text { Tsintsicha-A } & \text { y }\end{array}$

tsitsispahndaquare ca yrecha tariacurini

Tsitsispahndaquare ca yrecha Tariacuri-ni

Tsitsispahndaquare y rey Tariacuri-A

$Y$ se dice que de regreso el rey don Antonio Tsiuangua se mostró en Xaraquaro, el valiente que tiene ${ }^{16}$ la tierra y el pueblo aquí en Xaraquaro. Y entonces él también engendró a Francisco Tsintsicha, a Tsitsipandaquare y al rey Tariacuri.

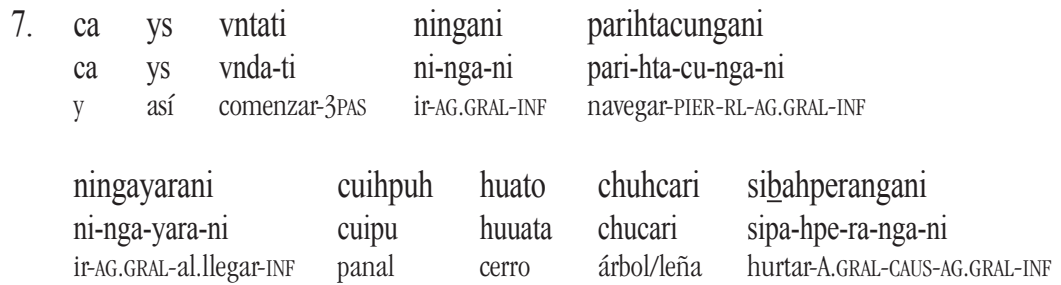

$\begin{array}{llllll}\text { ca } & \text { ys } & \text { vn[f.12r]tati } & \text { quarucuperangani } & \mathrm{p}[. .] 0 & \text { no } \\ \text { ca } & \text { ys } & \text { vnda-ti } & \text { qua-ru-cu-hpe-ra-nga-ni } & ? & \text { no } \\ \text { y } & \text { así } & \text { comenzar-3PAS } & \text { proteger-PROT-RL-A.GRAL-CAUS-AG.GRAL-INF } & ? & \text { no }\end{array}$

$\begin{array}{llllll}\begin{array}{llll}\text { vingavaquaregani } \\ \text { vinga-ua-quare-nga-ni }\end{array} & \begin{array}{l}\text { chuhcari } \\ \text { chucari }\end{array} & \begin{array}{l}\text { ca } \\ \text { ca }\end{array} & \begin{array}{l}\text { himahcanxsi } \\ \text { himahcan }=\text { n }\end{array} & \begin{array}{l}\text { niti } \\ \text { ni-ti }\end{array} \\ \text { árbol/leña } & \text { y } & \text { cuando=3PL } & \text { ir-3PAS }\end{array}$

$\begin{array}{llllll}\text { tariacuri } & \text { cathu } & \text { ynxsi } & \text { hayarati } & \text { tsimi } & \text { yrechecha } \\ \text { Tariacuri } & \mathrm{ca}=\mathrm{htu} & \mathrm{y}=\mathrm{n}=\mathrm{x} & \text { ha-yara-ti } & \text { tsimi } & \text { yrecha-echa } \\ \text { Tariacuri } & \mathrm{y}=\text { TAMB } & \text { este=ENF=3PL } & \text { tener/estar-al.llegar-3PAS } & \text { esos.ahí } & \text { rey-PL }\end{array}$

$\begin{array}{lllll}\text { hima } & \text { thicuintzequaro } & \text { ca } & \text { himacan } & \text { hunquangati } \\ \text { hima } & \text { Thicuintzequaro } & \text { ca } & \text { himahcan } & \text { hungua-nga-ti } \\ \text { allá } & \text { Thicuintzequaro } & \text { y } & \text { cuando } & \text { regresar-AG.GRAL-3PAS }\end{array}$

${ }^{16}$ Hapinca se podría traducir como 'el posee', sin embargo dicha posesión no debe entenderse como propiedad que puede venderse. 


$\begin{array}{lllll}\text { quangari } & \text { echa } & \text { antumucha } & \text { huangani } & \text { chucari } \\ \text { quangari } & \text { echa } & \text { andu-mu-echa } & \text { huua-nga-ni } & \text { chucari } \\ \text { valiente } & \text { PL } & \text { honra-boca-PL } & \text { venir-AG.GRAL-INF } & \text { árbol/leña }\end{array}$

$Y$ asi [los reyes] $]^{17}$ empezaron a ir, iban remando [y] llegaron al cerro del panal de árbol. Robaron leña. Y asi empezaron a hacer que les atajasen el paso [...] les negaban la leña. Y entonces esos reyes, don Francisco Tsintsicha y Tsitsispantaquare y Tariacuri, se fueron. Y también estos reyes se quedaron allá en Thicuintzequaro. Y entonces los bonorables valientes regresaron, trajeron la leña.

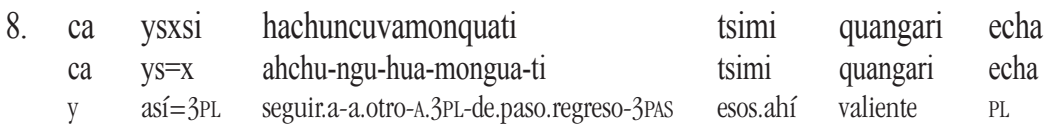

$\begin{array}{lllll}\text { pareo } & \text { yreti } & \text { echa } & \text { uanticuhhuacuecani } & \text { no } \\ \text { Pareo } & \text { yre-ti } & \text { echa } & \text { vua-ndi-cu-hua-cueca-ni } & \text { no } \\ \text { Pareo } & \text { morar-Sust } & \text { PL } & \text { golpear-ANG.R-RL-A.3PL-deseo-INF } & \text { no }\end{array}$

$\begin{array}{llll}\text { uigauaquareni } & \text { chucari } & \text { ca } & \text { hutixsi } \\ \text { vinca-ua-quare-ni } & \text { chucari } & \text { ca } & \text { hu-ti=x } \\ \text { fuerte-ESTÓM-ACC.IND-INF } & \text { árbol.leña } & \text { y } & \text { salir-3PAS=3PL }\end{array}$

$\begin{array}{lllll}\text { hachuvahmonquani } & \text { cantsimaqua }^{18} & \text { himbo } & \text { ca } & \text { himahcanxsi } \\ \text { achu-hua-mongua-ni } & \text { cantza-ma-qua } & \text { himbo } & \text { ca } & \text { himahcan=x } \\ \text { seguir.a-A.3PL-de.paso.regreso-INF } & \text { reja-LIQ-SUST } & \text { por } & \text { y } & \text { cuando=3PL }\end{array}$

$\begin{array}{llll}\text { hauarasti } & \text { tsimi } & \text { yrechecha } & \text { ton fran }^{\text {co }} \\ \text { haua-ra-s-ti } & \text { tsimi } & \text { yrecha-echa } & \text { don Francisco } \\ \text { levantarse-CAus-PERF-3 } & \text { esos.ahí } & \text { rey-PL } & \text { don Francisco }\end{array}$

$\begin{array}{lllllll}\text { tsintsicha } & \text { ca } & \text { tsitsispahntaquare } & \text { ca } & \text { tariacuri } & \text { ca } & \text { ysxsi } \\ \text { Tsintsicha } & \text { ca } & \text { Tsitsispahntaquare } & \text { ca } & \text { Tariacuri } & \text { ca } & \text { ys=x } \\ \text { Tsintsicha } & \text { y } & \text { Tsitsispahntaquare } & \text { y } & \text { Tariacuri } & \text { y } & \text { así=3PL }\end{array}$

${ }^{17}$ En la frase verbal vntati ningani paribtacungani ningayarani, el sufijo nga, que funciona para indicar que el sujeto refiere a varias entidades, permite reconstruir como sujeto a los reyes mencionados en la oración anterior. Podría sin embargo interpretarse el sufijo nga como impersonal, en tal caso toda la oración inicial del presente párrafo se traduciría con impersonal: 'así se empezó a ir, se fueron remando [...]'.

${ }^{18}$ Reconstruimos cantza-ma-qua. El Diccionario Grande de la Lengua de Michoacán (1991) ofrece la entrada "Cantzamequa. Balsa". 


$\begin{array}{lllll}\text { havasti } & \text { quahnimahhuani } & \text { uuinpipetaqua } & \text { hinbo } & \text { tsimini } \\ \text { haua-s-ti } & \text { quani-ma-hua-ni } & \text { vimbimbeta-qua } & \text { himbo } & \text { tsimi-ni } \\ \text { levantarse-PERF-3 } & \text { arrojar-LIQ-A.3PL-INF } & \text { honda-Sust } & \text { por } & \text { esos.ahí-A }\end{array}$

$\begin{array}{lllllll}\text { quangari } & \text { echani } & \text { bareo } & \text { yreti } & \text { echani } & \text { ca } & \text { ysxsi } \\ \text { quangari } & \text { echa-ni } & \text { Pareo } & \text { yre-ti } & \text { echa-ni } & \text { ca } & \text { ys }=\text { x } \\ \text { valiente } & \text { PL-A } & \text { Pareo } & \text { morar-Sust } & \text { PL-A } & \text { y } & \text { así =3PL }\end{array}$

$Y$ así los valientes habitantes de Pareo los seguían de regreso y en un tramo los quisieron matar, les negaron la leña. Los siguieron de regreso en balsas de rama. Y entonces los reyes, don Francisco Tsintsicha y Tsitsispahndaquare y Tariacuri, tuvieron que levantarse. Y así ellos se levantaron, a esos valientes habitantes de Pareo en el agua les tiraron con onda. Y así ellos

$\begin{array}{llllll}\text { 9. } & \text { esti } & \text { tsimint } & \text { pareo } & \text { yreti } & \text { tanimutt } \\ \text { pa-cu-mu-ns-cata } & \text { e-s-ti } & \text { tsimi } & \text { Pareo } & \text { yre-ti } & \text { tanimu } \\ \text { llevar-BENEF.3-TRAY-CONS-SUST } & \text { ser-PERF-3 } & \text { esos.ahí } & \text { Pareo } & \text { morar-sust } & \text { tres }\end{array}$

$\begin{array}{ll}\text { yraqua: } & \text { ea } \\ \text { yra-qua } & \text { ca } \\ \text { redondo-sust } & \text { y }\end{array}$

esclavos son ellos tres habitantes subyugados de Pareo $y^{20}$

\begin{tabular}{|c|c|c|c|c|c|c|}
\hline 10. ys & niti & yrecha & $\underline{\text { ton fran }}{ }^{\mathrm{co}}$ & tsin/tsicha & ea & tsitsipahntaquare \\
\hline ys & ni-ti & yrecha & don Francisco & Tsintsicha & $\mathrm{ca}$ & Tsitsispahntaquare \\
\hline así & ir-3PAS & rey & don Francisco & Tsintsicha & $\mathrm{y}$ & Tsitsispahntaquare \\
\hline
\end{tabular}

$\begin{array}{lllllll}\text { parihtacuni } & \text { toquaro } & \text { ca } & \text { vti } & \text { yacata } & \text { ca } & \text { hima [..]ini } \\ \text { pari-hta-cu-ni } & \text { Toquaro } & \text { ca } & \text { v-ti } & \text { yyacata } & \text { ca } & \text { hima } \\ \text { navegar-PIER-RL-INF } & \text { Toquaro } & \text { y } & \text { hacer-3PAS } & \text { yácata } & \text { y } & \text { allá }\end{array}$

minquaresti echeri:

minguare-s-ti eche-ri

allegar-PERF-3 tierra-susT

Así se fue el rey don Francisco Tsintsicha y navegó en canoa a Toquaro y construyó una yácata. Y allá tomó dominio de la tierra.

19 Reconstruimos bacumunscata. El Diccionario Grande de la Lengua de Michoacan (1991) contiene la entrada "Esclauo alcançado en guerra. Pacumunscata.".

${ }^{20}$ El término yraqua remite a una cosa redonda (Diccionario Grande de la Lengua de Michoacán) y parece reforzar el aspecto de la esclavitud de los sobrevivientes de Pareo quienes tras el enfrentamiento aparentemente se quedaron acostados con el cuerpo doblado o sentados en cuclillas, indicación de que fueron tomados prisioneros. Véanse p. e. los cautivos pintados en la Relación de Michoacán (Alcalá, 2000: 520, 589). 


$\begin{array}{lllll}\text { 11. vntabarini } & \text { ychachuen } & \text { ca } & \text { himanqua } & \text { havahenani } \\ \text { vnda-pa-ri-ni } & \text { ychachuen } & \text { ca } & \text { himangua } & \text { haua-hena-ni } \\ \text { comenzar-de.ida-ESTC-INF } & \text { Ychachuen } & \text { y } & \text { luego.después } & \text { levantarse-PTO.PARTIDA-INF }\end{array}$

\begin{tabular}{|c|c|c|c|c|c|c|c|c|}
\hline harataro & $\mathrm{ca}$ & hima & \multicolumn{3}{|c|}{ hauahenani } & \multicolumn{3}{|c|}{ huringequaro } \\
\hline Arataro & ca & hima & \multicolumn{3}{|c|}{ haua-hena-ni } & \multicolumn{3}{|c|}{ Huringuequaro } \\
\hline Arataro & $\mathrm{y}$ & allá & \multicolumn{3}{|c|}{ levantarse-PTO.PARTIDA-INF } & \multicolumn{3}{|c|}{ Huringuequaro } \\
\hline minta & $\mathrm{ma}$ & tzacapu & cruz & hucati & $\mathrm{ca}$ & hima & \multirow{3}{*}{\multicolumn{2}{|c|}{$\begin{array}{l}\text { havahenani } \\
\text { haua-hena-ni } \\
\text { levantarse-PTO.PARTIDA-INF }\end{array}$}} \\
\hline minda & ma & tzacapu & crus & huca-ti & $\mathrm{ca}$ & hima & & \\
\hline 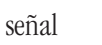 & una & piedra & cruz & tener-3PAS & y & allá & & \\
\hline \multicolumn{2}{|l|}{ niyarani } & \multicolumn{2}{|c|}{ thincuintzequaro } & \multicolumn{2}{|l|}{ hati } & minta & \multicolumn{2}{|c|}{ thamu } \\
\hline \multirow{2}{*}{\multicolumn{2}{|c|}{$\begin{array}{l}\text { ni-yara-ni } \\
\text { ir-al.llegar-Is }\end{array}$}} & \multirow{2}{*}{\multicolumn{2}{|c|}{ Thincuintzequaro }} & \multicolumn{2}{|l|}{ ha-ti } & minda & \multicolumn{2}{|c|}{ thamu } \\
\hline & & & & tener/est: & 3PAS & señal & cuat & \\
\hline
\end{tabular}

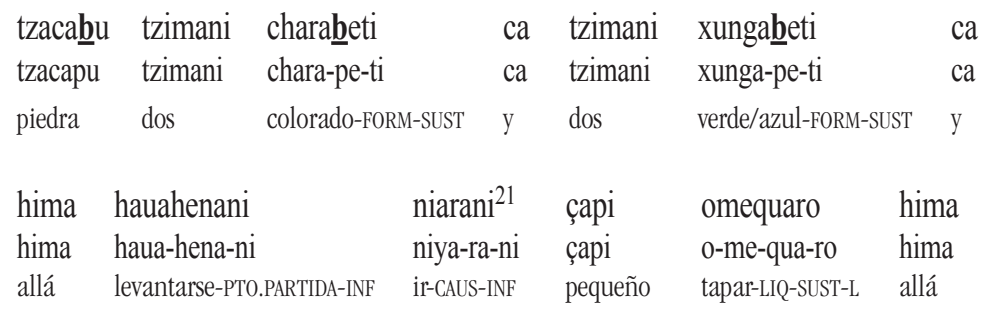

$\begin{array}{llllll}\text { hatini } & \text { eratacuqua } & \text { eti } & \text { ychachutiro } & \text { ys } & \text { yncharini } \\ \text { ha-ti=ni } & \text { era-hta-cu-qua } & \text { e-ti } & \text { ycha-hchu-ti-ro } & \text { ys } & \text { yncha-ri-ni } \\ \text { tener/estar-3PAS=ENF } & \text { ver-pier-RL-Sust } & \text { ser-3PAS } & \text { largo-TRASE-SUST-L } & \text { así } & \text { entrar-ESTC-INF }\end{array}$

$\begin{array}{llllll}\text { huvataro }= & \text { hati } & \text { ma } & \text { quehrenta } & \text { quehri } & \text { angarucuti } \\ \text { huuata-ro } & \text { ha-ti } & \text { ma } & \text { querenda } & \text { caheri } & \text { anga-ru-cu-ti } \\ \text { cerro-L } & \text { tener/estar-3PAS } & \text { una } & \text { peña } & \text { grande } & \text { erecto-PROT-RL-3PAS }\end{array}$

Comenzó en Ychachuen. Y luego se fue a Arataro. Y de allá se fue a Huringuequaro [donde] bay como señal una piedra que tiene una cruz. Y de allá partió para llegar a Thincuintzequaro [donde] bay una señal de cuatro piedras, dos rojas y dos verdes. Y de allá partió para llegar a una isla pequeña, allá hay un mojón, está en la parte baja de un lugar alargado, así en lo profundo del cerro [donde] bay un peñasco grande [que] se yergue en la orilla.

${ }^{21}$ Este escribano registra la raíz como nia que podría ser una errata gráfica para representar la raíz niya, o podría corresponder a un cambio de pronunciación. 


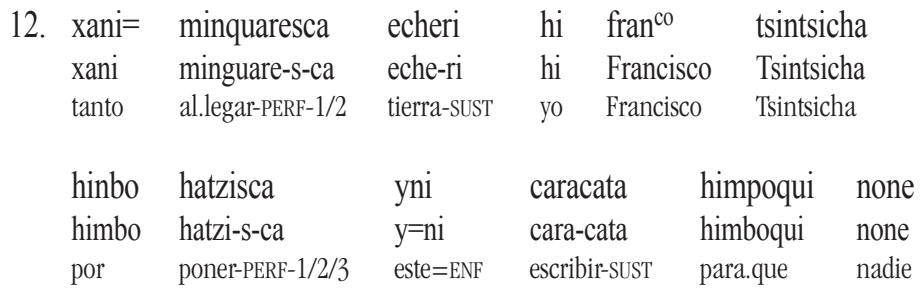

$\begin{array}{llll}\text { cahraquarenstavaca } & \text { echeri } & \text { hecamaqua } & \text { himpo } \\ \text { cara-quare-nsta-ua-ca } & \text { eche-ri } & \text { ehcama-qua } & \text { himbo } \\ \text { escribir-ACC.IND-CONS-FUT-1/2/3 } & \text { tierra-SuST } & \text { mentir-SUST } & \text { por }\end{array}$

$\begin{array}{llll}\text { himpoquixsingate } & \text { yamento } & \text { tarequarevaca } & \text { hucheue } \\ \text { himboqui=x=ngate } & \text { yamendo } & \text { tare-quare-ua-ca } & \text { hucheue } \\ \text { para.que=3PL=miserable } & \text { todos } & \text { cavar-ACC.IND-FuT-1/2/3 } & \mathrm{mi}\end{array}$

$\begin{array}{lllllll}\text { hincun } & \text { equa } & \text { echa } & \text { ca [..] } & \text { vtas } & \text { quaquareua } & \text { echeri } \\ \text { hinguni } & \text { e-qua } & \text { echa } & \text { caxsi } & \text { vtas } & \text { qua-quare-ua } & \text { eche-ri } \\ \text { con } & \text { ser-sust } & \text { PL } & \text { y=3PL } & \text { siempre } & \text { proteger-ACC.IND-FUT.INTERR } & \text { tierra-SUST }\end{array}$

$\begin{array}{lll}\text { xarataparini } & \text { yni } & {[\ldots] 0^{22}} \\ \text { xara-ta-pa-ri-ni } & \text { y=ni } & ? \\ \text { manifestar-CAus-de.ida-ESTC-INF } & \text { este-ENF } & ?\end{array}$

Tanto asi yo, don Francisco Tsintsicha, tengo dominio sobre la tierra, por eso yo este escrito lo hice para que nadie escriba mentiras sobre la tierra, para que todos ellos, pobrecillos, las labren conmigo. ¿Y siempre protegerán la tierra? Se ha venido mostrando esta [...]

$\begin{array}{llllll}\text { 13. a } & \text { menchunteni } & \text { hunquapiringa } & \text { caxsi } & {[\ldots] \text { ni }} & \text { exepirini } \\ \text { a } & \text { men=chunde=ni } & \text { hungua-pirin-ca } & \text { ca }=\mathrm{x} & \text { ni } & \text { exe-pirin- } \mathrm{i} \\ \text { AUX } & \text { una.vez=de.veras=1SG } & \text { regresar-CoND- } 1 / 2 & \mathrm{y}=3 \mathrm{PL} & ? & \text { ver-COND-INTERR }\end{array}$

$\begin{array}{llllll}\text { ysquihtsi } & \text { nah } & \text { pahmzperapi[...]ca } & \text { yamento } & \text { cuihri[f.12v]pu } & \text { echa } \\ \text { ysqui=htsi } & \text { nah } & \text { pampz-hpera-pirin-ca } & \text { yamendo } & \text { cuiripu } & \text { echa } \\ \text { como/que=2PL } & \text { cómo } & \text { amar-RECIP-COND-1/2/3 } & \text { todo } & \text { persona } & \text { PL }\end{array}$

$\begin{array}{llllll}\text { ysqui } & \text { xani } & {[\ldots] \text { vaca }} & \text { ca } & \text { himbohtuni } & \text { vantanstasirahaca } \\ \text { ysqui } & \text { xani } & \text { ?-ua-ca } & \text { ca } & \text { himbo=htu=ni } & \text { vanda-nsta-sira-ha-ca } \\ \text { como/que } & \text { tanto } & \text { ?-FuT-1/2/3 } & \text { y } & \text { por=TAMB=1SG } & \text { hablar-CONS-HAB-PRES-1/2/3 }\end{array}$

${ }^{22}$ Esta palabra ilegible se encuentra en medio de dos dibujos de columnas/plumas. 


$\begin{array}{lllllll}\text { yni } & \text { yreta } & \text { himbo } & \text { toquaro } & \text { tsiminqua } & \text { yrechecha } & \text { ys } \\ \text { y=ni } & \text { yre-ta } & \text { himbo } & \text { Tocuaro } & \text { tsimi=nguan } & \text { yrecha-echa } & \text { ys } \\ \text { este=ENF } & \text { morar-SUsT } & \text { por } & \text { Tocuaro } & \text { esos.ahí=REP } & \text { rey-PL } & \text { así }\end{array}$

vantanstasirahati

vanda-nsta-sira-ha-ti

hablar-CONS-HAB-PRES-3

Si regresase una vez y ellos viesen [...] cómo ustedes, todas las personas, se aman los unos a los otros, que tanto así [...] y por eso también sobre este pueblo acostumbro bablar porque dicen que en Tocuaro los reyes asi acostumbran hablar.

$\begin{array}{llllllll}\text { 14. ca } & \text { ys } & \text { niti } & \text { yrecha } & \text { ton } & \text { fran }^{\mathrm{co}} & \text { tariacuri } & \text { niarani } \\ \text { ca } & \text { ys } & \text { ni-ti } & \text { yrecha } & \text { don } & \text { Francisco } & \text { Tariacuri } & \text { niya-ra-ni } \\ \text { y } & \text { así } & \text { ir-3PAS } & \text { rey } & \text { don } & \text { Francisco } & \text { Tariacuri } & \text { ir-CAUS-INF }\end{array}$

$\begin{array}{llllll}\text { cuirinquaro } & \text { cathu } & \text { vini } & \text { harasti } & \text { cuirinquaro } & \text { quahngari } \\ \text { Cuiringuaro } & \text { ca=htu } & \text { vini } & \text { hara-s-ti } & \text { Cuiringuaro } & \text { quangari } \\ \text { Cuiringuaro } & \text { y=TAMB } & \text { llenar } & \text { estar-PERF-3 } & \text { Cuiringuaro } & \text { valiente }\end{array}$

tharenpoh[.]ha ca ys hunquati quahngatzenstan honoquani:

tare-mba-echa ca ys hungua-ti qhuanga-tze-nsta-ni hono-ngua-ni

cavar-P0S3-PL y así regresar-3PAS regresar-S.INF-CONS-INF llegar-TRAY-INF

mintzin pahzquaro

mintzin Pahzquaro

grande Patzcuaro

Y así el rey don Francisco Tariacuri se fue, llegó a Cuiringuaro. Y también Cuiringuaro estaba lleno de sus valientes labradores [que] regresaba(n), bajaban regresando del gran Pátzcuaro.

$\begin{array}{llllll}\text { 15. ca } & \text { himacani } & \text { axasti } & \text { vantaqua } & \text { cuirinquaro } & \text { yreti } \\ \text { ca } & \text { himahcan } & \text { axa-s-ti } & \text { vanda-qua } & \text { Cuiringuaro } & \text { yre-ti } \\ \text { y } & \text { cuando } & \text { enviar-PERF-3 } & \text { hablar-sust } & \text { Cuiringuaro } & \text { morar-susT }\end{array}$

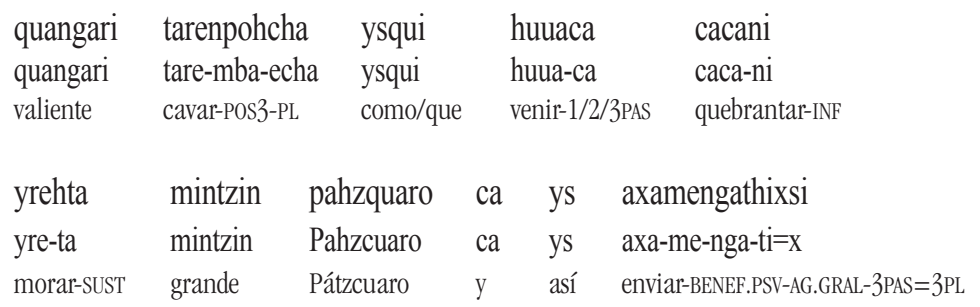




\begin{tabular}{|c|c|c|c|c|c|c|}
\hline $\begin{array}{l}\text { vuantaqua } \\
\text { vanda-qua } \\
\text { hablar-sust }\end{array}$ & $\begin{array}{l}\text { yrechecha } \\
\text { yrecha-echa } \\
\text { rey-PL }\end{array}$ & $\begin{array}{l}\text { siuini } \\
\text { siuini } \\
\text { remolino }\end{array}$ & \multicolumn{2}{|c|}{$\begin{array}{l}\text { ysqui } \\
\text { ysqui } \\
\text { como/que }\end{array}$} & \multicolumn{2}{|c|}{$\begin{array}{l}\text { cacangacuecahaca } \\
\text { caca-nga-cueca-ha-ca } \\
\text { quebrantar-AG.GRAL-EXPECT-PRES-1/2/. }\end{array}$} \\
\hline$a$ & mintzin & aro & $\mathrm{ca}$ & ysxsi & vntati & nirani \\
\hline & mintzin & Pahzcuaro & $\mathrm{ca}$ & $\mathrm{ys}=\mathrm{x}$ & vnda-ti & ni-ra-ni \\
\hline & grande & Pátzcuaro & y & así=3PL & empezar-3PAS & ir-CAUS-INF \\
\hline
\end{tabular}

$\begin{array}{llll}\text { yrechecha } & \text { ayoca } & \text { cess } & \text { ma } \\ \text { yrecha-echa } & \text { haya-nga } & \text { cez } & \text { ma } \\ \text { rey-PL } & \text { contento-AG.GRAL } & \text { bien } & \text { uno }\end{array}$

Y entonces los valientes labradores, habitantes de Cuiringuaro, mandan su palabra de cómo irían a destruir al gran pueblo de Pátzcuaro, y así a los reyes 'siuini' (remolino) se les comunicó la palabra de que querían destruir al gran pueblo de Pátzcuaro. Y así los reyes empezaron a irse muy satisfechos.

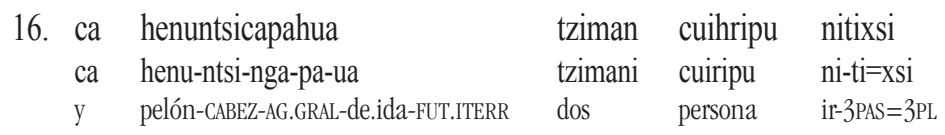

$\begin{array}{llllll}\text { harahr } & \text { atsintan } & \text { ys } & \text { ca } & \text { tzimani } & \text { cuihripu } \\ \text { harare } & \text { ahtsi-nda-ni } & \text { ys } & \text { ca } & \text { tzimani } & \text { cuiripu } \\ \text { apartarse } & \text { derramar-REDOR-INF } & \text { así } & \text { y } & \text { dos } & \text { persona }\end{array}$

$\begin{array}{lllllll}\text { nitixsi } & \text { thivapu } & \text { huvata } & \text { ys } & \text { ca } & \text { himaxsi } & \text { cuncuri } \\ \text { ni-ti=x } & \text { Thiuapu } & \text { huuata } & \text { ys } & \text { ca } & \text { hima=x } & \text { cu-nguri-ni } \\ \text { ir-3PAS=3PL } & \text { Thiuapu } & \text { cerro } & \text { así } & \text { y } & \text { allá=3PL } & \text { encontrar-dos-INF }\end{array}$

$\begin{array}{llllll}\begin{array}{l}\text { ensti } \\ \text { e-nsta-ti } \\ \text { ser-cons-3PAS }\end{array} & \begin{array}{l}\text { echuhueni } \\ \text { echuhueni } \\ \text { Echuhueni }\end{array} & \begin{array}{l}\text { cathu } \\ \text { ca=htu } \\ \text { y=TAMB }\end{array} & \begin{array}{l}\text { uini } \\ \text { vini-ni } \\ \text { llenar-INF }\end{array} & \begin{array}{l}\text { hurasinti } \\ \text { hura-sin-ti } \\ \text { venir-PRoSPECT-3 }\end{array} & \\ \text { cuirinquaro } & \text { yreti } & \text { quahngari } & \text { tharenb[...]a } & \text { mintzin } & \text { pahzquaro } \\ \text { Cuiringuaro } & \text { yre-ti } & \text { quangari } & \text { tare-mba-echa } & \text { mintzin } & \text { Pahzquaro } \\ \text { Cuiringuaro } & \text { morar-SusT } & \text { valiente } & \text { cavar-Pos3-PL } & \text { grande } & \text { Pátzcuaro }\end{array}$

$\begin{array}{lllll}\text { Cacacuecani } & \text { yreta } & \text { ca } & \text { nothiqui } & \text { huriata } \\ \text { caca-cueca-ni } & \text { yre-ta } & \text { ca } & \text { no=tihqui } & \text { huriyata } \\ \text { quebrantar-EXPECT-INF } & \text { morar-SUST } & \text { y } & \text { no=DELLIMI } & \text { sol }\end{array}$




$\begin{array}{lll}\text { angachemotiro } & \text { yamentoxsi } & \text { ahpesti } \\ \text { anga-nche-mo-ti-ro } & \text { yamendo=x } & \text { a-hpe-s-ti } \\ \text { erecto-arriba-de.paso.regreso-SUST-L } & \text { todo=3PL } & \text { AUX-A.GRAL-PERF-3 }\end{array}$

$\begin{array}{lll}\text { vanticuhpeni } & \text { hicha } & \text { yrechecha } \\ \text { vua-ndi-cu-hpe-ni } & \text { hihcha } & \text { yrecha-echa } \\ \text { golpear-ANG.R-RL-A.GRAL-INF } & \text { aquellos } & \text { rey-PL }\end{array}$

¿Serían dos personas rapadas? Ellas se fueron, se apartaron, así se dispersaron por los alrededores. Y asífueron las dos personas las que se fueron al cerro Thiuapu, y los dos se juntaron allá en Echubueni. Y también los habitantes y valientes labradores de Cuiringuaro iban ${ }^{23}$ decididos a llenar al gran Pátzcuaro, querian destruir al pueblo. Antes de que fuese medio día todos aquellos reyes los mataron. ${ }^{24}$
17. ca untatixsi
hun=quani
ayancumonquani
ca vnda-ti $=\mathbf{x}$
hungua-ni
aya-ngu-mongua-ni
y comenzar-3PAS=3PL regresar-INF
comunicar-a.otro-de.paso.regreso-INF

$\begin{array}{llllll}\text { yrechani } & \text { ton } & \text { fran }^{\text {co }} & \text { tariacurini } & \text { ysquixsi } & \text { yamento } \\ \text { yrecha-ni } & \text { don } & \text { Francisco } & \text { Tariacuri-ni } & \text { ysqui=x } & \text { yamendo } \\ \text { rey-A } & \text { don } & \text { Francisco } & \text { Tariacuri-A } & \text { como/que=3PL } & \text { todo }\end{array}$

\begin{tabular}{|c|c|c|c|c|c|}
\hline haspesca & \multicolumn{3}{|c|}{ vanticuhpeni } & na & xan \\
\hline $\begin{array}{l}\text { ha-pe-s-ca } \\
\text { tener/estar-suelo-PERF-1/2/3 }\end{array}$ & \multicolumn{3}{|c|}{$\begin{array}{l}\text { vua-ndi-cu-hpe-ni } \\
\text { golpear-ANG.R-RL-A.GRAL-INF }\end{array}$} & $\begin{array}{l}\text { nah } \\
\text { así }\end{array}$ & $\begin{array}{l}\text { xani } \\
\text { tanto }\end{array}$ \\
\hline ti & yrecha & don & \multicolumn{2}{|c|}{ fran ${ }^{c c}$} & tariacuri \\
\hline quare-s-ti & yrecha & don & \multicolumn{2}{|c|}{ Francisco } & Tariacuri \\
\hline tento-ACC.IND-PERF-3 & & don & \multicolumn{3}{|c|}{ Francisco } \\
\hline
\end{tabular}

Y ellos empezaron a regresar, en el camino se pararon a comunicarle al rey don Francisco Tariacuri que todos estaban en la planicie matándolos. Cuán contento estaba el rey don Francisco Tariacuri.

${ }^{23}$ La flexión de la conjugación verbal que se ha interpretado en lengua moderna como modo indicativo, tiempo presente, aspecto habitual, en la palabra hurasinti, siguiendo la interpretación de Gilberti "para decir que luego en la ora yran o vernan" y de Lagunas "hazerse en facto lo que significa el verbo a quien se ayunta" (Monzón, 2018), se le podría considerar como un aspecto que podría denominarse 'prospectivo-casi certero'.

${ }^{24}$ Nótese la diferencia entre vanticuhpeni y vahchacuhpeni: el primero indica que el golpe se recibe en la sien y se utiliza en el contexto de una batalla, mientras que el segundo se remite a un golpe en la nuca como castigo capital ordenado por el rey o por el petamuti, el sacerdote mayor (véase la pintura correspondiente en Alcalá, 2000: 334). 


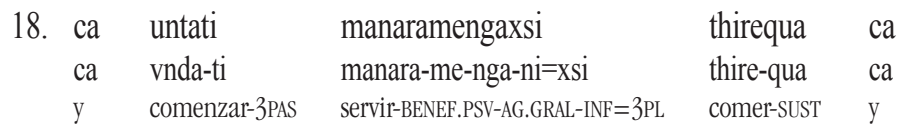

$\begin{array}{lllll}\text { untatixsi } & \text { ys } & \text { arini } & \text { yrechani } & \text { huchacuhche } \\ \text { vnda-ti=x } & \text { ys } & \text { ari-ni } & \text { yrecha-ni } & \text { hucha=cuhche } \\ \text { comenzar-3PAS=3PL } & \text { así } & \text { decir-INF } & \text { rey-A } & \text { nosotros=1PL }\end{array}$

$\begin{array}{llllll}\text { no } & \text { thirehca } & \text { yni } & \text { puhcu[...]raqua } & \text { hucha } & \text { thirehca } \\ \text { no } & \text { thire-ha-ca } & \text { y=ni } & \text { pucu-hcu-ra-qua } & \text { hucha } & \text { thire-ha-ca } \\ \text { no } & \text { comer-PRES-1/2 } & \text { este=ENF } & \text { frondoso-mano-E.Nom-Sust } & \text { nosotros } & \text { comer-PRES-1/2 }\end{array}$

$\begin{array}{lllllllll}\text { auani } & \text { ca } & \text { axuni } & {[\ldots]} & \text { acuitze } & \text { ca } & \text { cuhru } & \text { has } & \text { misquare } \\ \text { auani } & \text { ca } & \text { axuni } & \text { ca } & \text { acuitze } & \text { ca } & \text { curu } & \text { has } & \text { misquare } \\ \text { conejo } & \text { y } & \text { venado } & \text { y } & \text { culebra } & \text { y } & \text { codornices } & \text { no } & \text { aflicción }\end{array}$

$\begin{array}{llllll}\text { menchucare } & \text { hucha } & \text { eueri } & \text { si=ruri } & \text { esqui } & \text { quanga } \\ \text { menchuhca=re } & \text { hucha } & \text { eueri } & \text { siru-ri } & \text { e-s-qui } & \text { quangari } \\ \text { cierto=2sG } & \text { nosotros } & \text { Pos } & \text { linaje-susT } & \text { ser-PERF-INTERR } & \text { valiente }\end{array}$

$\begin{array}{llll}\text { himboxsini } & \text { huras=pihca } & \text { quahpens }[\ldots] \text { ni } & \text { çani } \\ \text { himbo }=x=\text { ni } & \text { hura-s-pih-ca } & \text { quahpe-nsta-ni } & \text { çani } \\ \text { por }=1 / 3=1 / 2 & \text { venir-PERF-PAS-1/2 } & \text { defender-CoNs-INF } & \text { poco }\end{array}$

$\begin{array}{llllll}\text { pacuhche } & \text { quahnga } & \text { ca } & \text { ys } & \text { vant }[. . .] & \text { nuntixsi } \\ \text { pa-ni=cuhche } & \text { quangari-cha-ni } & \text { ca } & \text { ys } & \text { vanda-ni } & \text { nunu-ti=x } \\ \text { llevar-INF=1PL } & \text { valiente-PL-AC } & \text { y } & \text { así } & \text { hablar-INF } & \text { mudo-3PAS=3PL }\end{array}$

Y se empezó a servirles comida. Y ellos empezaron a decirle asi al rey: nosotros esos brazos gordos ${ }^{25}$ no los comemos, nosotros comemos conejos, venados, culebras y codornices. Ciertamente no te aflijas ${ }^{26}$ [no se aflija usted]. ¿Nuestro linaje es valiente? Por eso nosotros venimos a defenderlos a ustedes, nosotros llevamos unos pocos ${ }^{27}$ valientes. Así bablamos. Ellos se quedaron mudos.

${ }^{25}$ En el Diccionario Grande de la Lengua de Michoacán (1991) se tiene "Pucuhcuraqua. Hoja de arbol." lo cual interpretamos con base al trasunto como refiriendo al cuerpo humano.

${ }^{26}$ Nótese el uso de la segunda persona singular indicada con el enclítico =re que se utilizó para hablar con respeto a una persona.

${ }^{27}$ El elemento çani se utiliza para comunicar respetuosamente, no que de hecho sean pocos. 


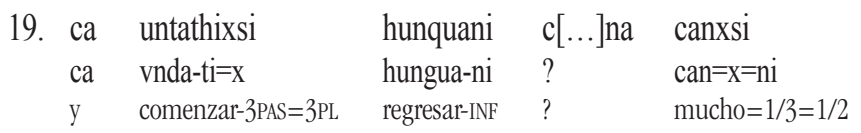

$\begin{array}{lllll}\text { huamengasti } & \text { yrechecha } & \text { [.]ris[.]aqua } & \text { ysqui } & \text { ya } \\ \text { vua-me-nga-s-ti } & \text { yrech-echa } & \text { ?-qua } & \text { ysqui } & \text { ya } \\ \text { golpear-BENEF.PSV-AG.GRAL-PERF-3 } & \text { rey-PL } & \text { ?-sus } & \text { como/que } & \text { ya }\end{array}$

$\begin{array}{llll}\text { hunga[f.13r]nosca } & \text { echero } & \text { espanole } & {[\ldots . . . . .]} \\ \text { hu-nga-no-s-ca } & \text { echero } & \text { espanole } & {[\ldots . . .]} \\ \text { venir-AG.GRAL-TRAY-PERP-1/2/3 } & \text { México } & \text { españoles } & {[\ldots . . .]}\end{array}$

Y ellos empezaron a regresar [...] los golpearon mucho para beneficio de los reyes [...] Entonces los españoles vinieron a México [.......]

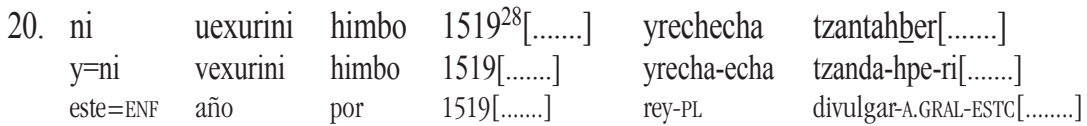

$\begin{array}{llllll}\text { tanberanganstani } & \text { ysqui } & {[\ldots . . . .]} & \text { no } & \text { vaca } & \text { zintzuntzani } \\ \text { ahtambe-ra-nga-nsta-ni } & \text { ysqui } & {[\ldots \ldots . .]} & \text { no } & \text { vua-ca } & \text { Tzintzuntzani } \\ \text { congregar-CAUS-AG.GRAL-CONS-INF } & \text { como/que } & {[\ldots . . . .]} & \text { no } & \text { golpear-1/2/3 } & \text { Tzintzuntzani }\end{array}$

$\begin{array}{llll}\text { ca } & \text { hun[........ } & \text { [.]uarenganstani } & \text { yrechec[.......] } \\ \text { ca } & \text { hu-[...... } & \text { [.]vua-re-nga-nsta-ni } & \text { yrecha-echa[......] } \\ \text { y } & \text { venir[....... } & \text { golpear-cuerpo-AG.GRAL-CONS-INF } & \text { rey-PL[....... }\end{array}$

$\begin{array}{lllllll}{[.] \text { ]erangani }} & \text { ysqui } & \text { nah } & \text { vqu[....... } & \text { ri } & \text { ysqui } & \text { hima } \\ \text { era-nga-ni } & \text { ysqui } & \text { nah } & \text { v-qua[....... } & \text { ri } & \text { ysqui } & \text { hima } \\ \text { ver-AG.GRAL-INF } & \text { como/que } & \text { cómo } & \text { hacer-sust } & \text { ? } & \text { como/que } & \text { allá }\end{array}$

$\begin{array}{lllllll}\text { vndauaca[....... } & \text { ngani } & \text { ysqui } & \text { xangari } & \text { hara[.......] } & \text { qui } & \text { hima } \\ \text { vnda-ua-ca[...... } & \text {-nga-ni } & \text { ysqui } & \text { xangari } & \text { hara[......] } & \text { yqui } & \text { hima } \\ \text { comenzar-FUT-1/2/3 } & \text {-AG.GRAL-INF } & \text { como/que } & \text { camino } & \text { estar[......] } & \text { entonces } & \text { allá }\end{array}$

hirihtzequareng[....... ratin habepirinca vant[....... tzuntzani hameri hiri-htze-quare-ng[.......] ? ? ? ?[......] Tzintzuntzani hameri esconder-SINF-ACC.IND-[.......] ? ? ?[......] Tzintzuntzan hasta

${ }^{28}$ El año se encuentra escrito al interior del dibujo de un marco completo, probablemente para enfatizar su importancia. 


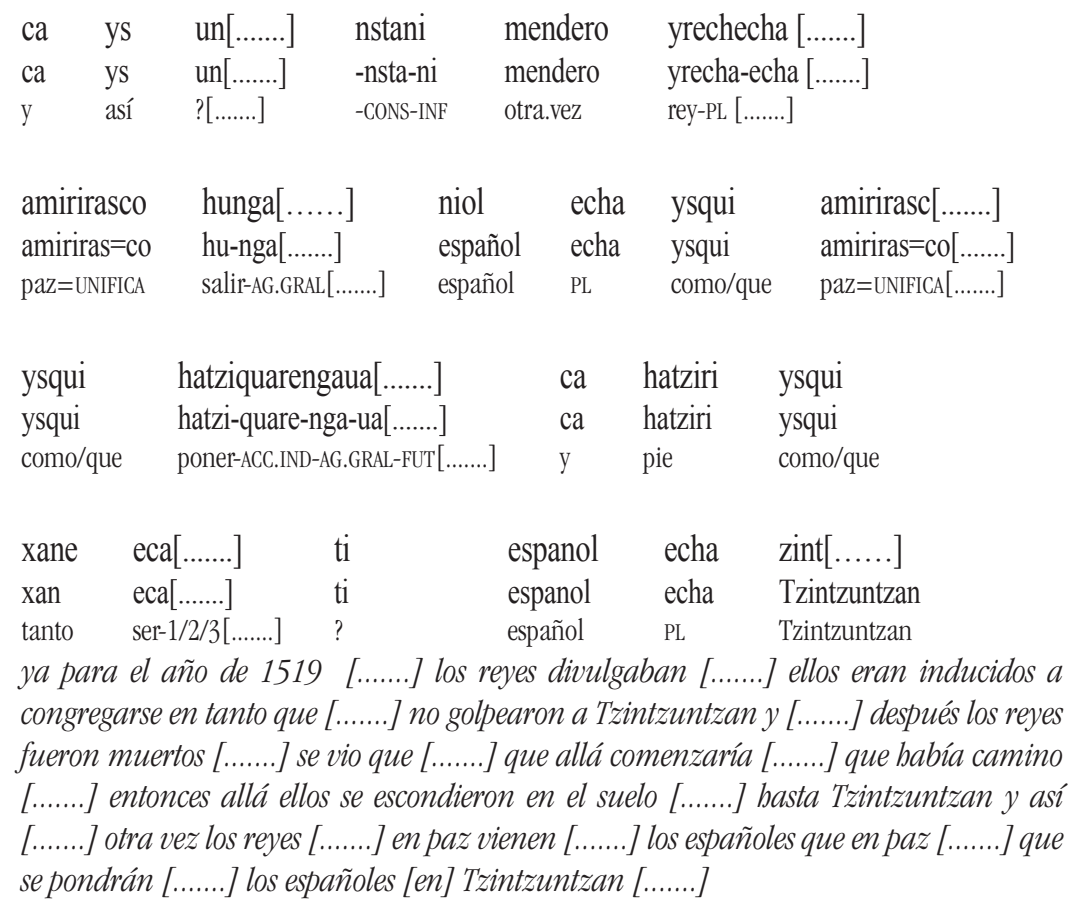

\section{Comentarios lingüústicos}

El registro ortográfico del texto tarasco observa las convenciones establecidas por los frailes desde la segunda mitad del siglo XvI, sin embargo hay algunas excepciones que sugieren que los carariecha (escribanos) buscaron encontrar una representación más congruente con su propia lengua. ${ }^{29}$ En el título aparecen, en un buen número de palabras, dos representaciones ortográficas alternativas para las convenciones $m b, n d, n g u$ de los religiosos, siendo la más frecuente $m p, n t, n q u$ o ncu. Esta práctica escrituraria de los escribanos nativos no es sorprendente pues los alófonos [b, d, g], cuya sonoridad resulta de la presencia de una nasal que los precede, son sonidos que los escuchas, en tanto hablantes del tarasco, no son conscientes de su existencia. Esta nueva secuencia gráfica es fiel al nivel fonémico de la lengua misma, no solo cuando los alófonos [b, d, g]

${ }^{29}$ Véase Monzón (2007) para una visión general de la búsqueda de nuevos registros ortográficos por parte de los hablantes mismos. 
se encuentran después de nasal sino también a principio de palabra registrando ton por don, en este caso con una excepción en el párrafo 17. La segunda opción, menos frecuente, es el uso de solo una consonante, $b, d$, g, en sustitución de la secuencia $m b, n d, n g$ registrada en las obras lingüísticas del siglo xVI. En consecuencia, cuando se consulten los vocabularios de la época para ubicar las palabras, el lector deberá sustituir las secuencias $m p, n t, n q u$ o ncu o las consonantes $b, d, g$, todas resaltadas en el texto estudiado con negritas, por $m b, n d, n g u$. Nótese además que la palabra himbo en el título se escribe con mucha frecuencia como hinbo.

Una tercera convención, igualmente marcada en negritas pero además subrayada, registra las grafías $b, d$, $g$ en posición intervocálica en lugar de las letras esperadas $p, t, c 0$ $q$. Esta particularidad ortográfica que se encuentra desde el inicio del texto hasta la mitad del párrafo 11, constituye un corte ya que a partir de la mitad o final de la misma oración no se vuelve a registrar este uso peculiar de consonantes intervocálicas. Casi coincidente con la ausencia de este hábito ortográfico, se tiene la presencia de la grafía $h r$ que permite diferenciar la $[r]$ vibrante retrofleja de la $[\mathrm{r}]$ vibrante alveolar-dental simple. Esta grafía la encontramos a partir del párrafo 11 hasta el final del texto. Por otro lado el uso de th en posición inicial e intervocálica se encuentra repartido a lo largo de todo el título mientras que $p h$ únicamente aparece en la palabra phitaqua del párrafo 5, quedando totalmente ausente la representación del resto de las consonantes aspiradas. El uso poco sistemático de estas consonantes aspiradas refleja el limitado impacto de la obra Arte y Diccionario con otras obras en Lengua Michuacana de fray Juan Baptista de Lagunas (1574) en la formación y práctica de los escribanos indígenas. Por otra parte, la convención gráfica de nasal aspirada se encuentra siempre en el nombre del rey tsitsispahndaquare y en la raíz quahni, un uso limitado que podría interpretarse como reminiscencia de una pronunciación antigua. Se cuenta además con dos ejemplos de $h m$ en los párrafos 8 y 13, aunque los escribanos del título tienen la tendencia de introducir la aspiración $b$ reduplicando esta letra o ubicándola incorrectamente.

Tomando en consideración las convenciones ortográficas compartidas entre los escribanos, en particular aquellas marcadas solamente con negritas y el uso de las secuencias $m p, n t, n q u$ o ncu, se podría sugerir que se formaron fuera de la influencia directa de los frailes y se inscriben más bien en un proceso de reflexión propia de los hablantes nativos. Las diferencias identificadas a partir de las últimas líneas del párrafo 11 sugieren a su vez que emplearon dos corrientes de prácticas ortográficas para desarrollar sus hábitos escriturales. Desafortunadamente se desconoce cuál fue para la época (siglos XVII-XVIII) el sistema de entrenamiento que recibían los escribanos michoacanos. 
A pesar de tratarse de un texto relativamente breve, por lo menos dos escribanos estuvieron involucrados en su elaboración. El primero se encargó de los párrafos 1 a 3 a los cuales les sigue una línea horizontal: aunque el color más oscuro de esta sección podría apuntar a una técnica particular u otro tipo de tinta o pluma de ave, llama la atención que el carari (escribano) en cuestión escribía de manera más cursiva en comparación con las intervenciones posteriores de sus colegas. También se distingue claramente por la grafía particular de la $z$ e $y$, entre otras letras. La palabra "titulo" en el margen izquierdo parece ser producto de la misma mano, a juzgar por la intensidad de la tinta y las particularidades gráficas, pero el término "toquaro" en el centro corresponde a la intervención de otro escribano. Las grafías en el resto del documento no muestran grandes variaciones y podrían corresponder a una sola mano, aunque existe otra sección redactada con tinta más oscura desde el segundo renglón del párrafo 8 hasta la segunda línea del párrafo 13, exactamente donde termina el folio 12r: al parecer se debe al cambio de tinta y/o pluma de ave, ya que a partir del folio $12 \mathrm{v}$ el color vuelve al tono más claro que predomina en el documento. No obstante, si el segundo carari fuera el único responsable a partir del párrafo 4, implicaría que este mezcló distintas convenciones ortográficas. Como señalamos arriba, llama la atención el peculiar registro de consonantes intervocálicas (hasta la mitad del párrafo 11) y el uso de la hr desde el párrafo 11 (después de la palabra xungabeti). En esta última sección se tiene además la presencia del símbolo de igual (=) para indicar fin de renglón (en dos ocasiones) o corte de palabra al terminar la línea (tres veces). Si estas características fueran producto de un tercer carari, esperaríamos encontrar evidencia adicional en las grafías, por lo que más bien parece que el segundo escribano mostró relativamente poca consistencia ortográfica.

En cuanto al tema de los cambios históricos en la lengua tarasca, podemos comentar que la palabra caheri del siglo xvi (significa 'grande') se encuentra como quebri en el párrafo 11 del título, siendo este el primer reporte de pérdida de la vocal a principio de palabra. Por otra parte la flexión verbal haca que fray Maturino Gilberti (Monzón, 2018: 55) identifica como tiempo presente modo indicativo y subjuntivo se le encuentra una única vez en el párrafo 15, además de nuevamente un solo ejemplo en el contexto del aspecto habitual en el párrafo 13. La transformación histórica que ha sufrido esta flexión verbal, - $h c a$, presenta la pérdida vocálica en dos ocasiones en el párrafo 18 donde se reporta la respuesta al rey Tariacuri: thirehca en modo indicativo.

En términos ortográficos el registro de la consonante aspirada con la letra $p h$, grafía que fray Juan Baptista de Lagunas propone en su Arte y Diccionario en lengua michoacana, se encuentra en nuestro texto una sola vez en el párrafo 5. El uso de la grafía $p h$ sugiere que el texto efectivamente es posterior a las dos últimas décadas del siglo XVI, pero 
con base al cambio fonológico de la flexión, sin duda es más tardío, quizás ya entrado el siglo XVII.

\section{Resumen del contenido}

A partir de la traducción literal del título, podemos realizar la siguiente lectura del conjunto, señalando además las diferencias existentes en los dos trasuntos (véase también la tabla 2). Al inicio del texto se comenta que contiene la memoria del rey Tsivanqua (variantes Tsiuanqua y Tsivaqua), la cual es guardada por sus parientes en muchos lugares. ${ }^{30}$ Se agrega como al principio se le encomendó vestirse únicamente con un cuero de animal y dedicarse a la caza de conejos, venados, culebras y codornices para su alimentación. Para este fin se le envió (no se dice de parte de quien) un arco y carcaj de flechas, además de un bezote de oro y un collar del mismo material. En ambos trasuntos, este episodio es interpretado como una ceremonia de coronación (en su traducción libre hablan de "como armaron rey" y "me armaron rey") en que el bezote es identificado como "mascarín". 31 Después de esta introducción sobre Tsivanqua, pero antes de iniciar la historia del poblamiento de Tócuaro (escrito como Toquaro) en que intervienen las voces de sus descendientes, se comenta que "esta es la ley por la que los ancianos son honorables", probablemente refiriéndose a la recepción de las insignias del poder por parte del rey. Se agrega que el poseedor de la honra es aquel que hace el testamento, al parecer remitiéndose a Tsivanqua como el autor del documento en que se transmite el pasado a sus herederos. Los trasuntos por su parte aluden a los mandatos de los valientes, indicando que todos ellos tenían la misma calidad, aparentemente refiriéndose al ser reyes y cazadores.

La parte central de la narración empieza con la migración del mencionado noble, aquí identificado con un nombre cristiano como el valiente rey don Antonio Tsivanqua, quien primero llegó (no se especifica su origen) a Guayangareo (Guayángareo, Valladolid en los trasuntos). ${ }^{32}$ Posteriormente se trasladó a Xenguaro (Xénguaro, Capula en

${ }^{30}$ El rey es identificado como el primer autor (figura en primera persona). En los trasuntos, su nombre viene escrito como "Tzivangua" (T-BNAH) y "Tziuangua" (T-NL).

${ }^{31}$ Cabe agregar que en las dos versiones se omite la mención de los parientes del rey.

32 Valladolid (el actual Morelia) es el nombre oficial que impusieron los españoles en 1577 o 1578, reemplazando el antiguo término tarasco Guayángareo (Herrejón Peredo, 2000: 155) que sin embargo seguía usándose en el medio indígena. 
los trasuntos), ${ }^{33}$ donde clavó flechas en las yácatas (pirámides), ${ }^{34}$ para continuar primero a Cutzaro y luego a Zintzuntzan (Tzintzuntzan), donde en las yácatas hizo volar a los colibriés. ${ }^{35}$ Finalmente arribó a la isla de Xanicho (Janitzio) donde prendió fuego en tres sitios (los trasuntos hablan de rayos) y clavó dos flechas. La huella del rey quedó marcada en una piedra, tras tropezarse en ella (según el original) o querer brincarla (conforme a los trasuntos). Saliendo de Janitzio, se fue a la otra isla vecina de Xaraquaro (Jarácuaro) donde llegó a poseer su pueblo y las tierras y donde engendró a tres hijos: Francisco Tsintsicha, Tsitsipahndaquare (variación Tsitsispahntaquare) y el rey Tariacuri. ${ }^{36}$ Es interesante observar que ambos trasuntos agregan información que no se encuentra en el título tarasco: especifican como Tsiuangua (nótese la ortografía distinta), parado en una yácata, tiró flechas hacia cuatro puntos (que probablemente correspondan a las direcciones cardinales) para deslindar y tomar en posesión las tierras del pueblo. ${ }^{37}$ Además, se especifica que el rey "por eso hiso este escrito que sirva de titulo" (T-NL, León, 1906: 106),,$^{38}$ es decir se relaciona el objetivo del documento directamente con la delimitación del territorio de Xaraquaro.

Los tres reyes, don Francisco Tsintsicha, Tsitsispahndaquare y Tariacuri, empezaron a remar (en canoa, especifican los trasuntos) y llegaron a Cuihpahhuato (Cuipuhuato) para juntar leña, en compañia de unos valientes.$^{39}$ No obstante, los valientes del pueblo de Pareo les cerraron el paso para impedirles que se llevaran su carga. Por lo tanto los

33 El término más antiguo parece haber sido el tarasco Xenguaro (Alcalá, 2000: 461, 523). Su equivalente en idioma náhuatl, Capula, fue empleado desde la Colonia temprana, ya que p.e. aparece en la tasación de Ortega de 1528 (Warren, 1989: 415-416). Ambos significan 'lugar de cerezas', refiriéndose a la variante mesoamericana.

${ }^{34}$ En los dos trasuntos no se habla de la yácata sino de un edificio. Cabe agregar que en la actualidad, el término es usado para referirse a las pirámides tarascas, sobre todo — pero no exclusivamente — las que tienen una base semicircular. Se desconoce el origen de la palabra ya que no aparece en los diccionarios tarascos del siglo xvi.

${ }^{35}$ Los dos trasuntos ubican el episodio en Cutzaro, omiten el topónimo Tzintzuntzan y hablan de pájaros (no mencionan los colibríes).

36 En los trasuntos, el segundo rey aparece como "Tzitzisphandaquare" (T-BNAH) y "Tzitris jopandaguare" (T-NL).

${ }^{37}$ Los cuatro lugares son (partiendo del T-BNAH): el puesto de "Thinguintzequaro" ("Ahinga entrecuaro" en el T-NL), el puesto con la piedra que tiene las huellas de pie de Tsiuangua, el puesto de "Napilo" ("Napijo" en el T-NL) donde está un cerrillo y una piedra grande con la señal de una flecha, y finalmente el pie de un cerrillo donde se encuentra un montón de piedras.

${ }^{38}$ En el T-BNAH se alcanza leer "por esso hisso este escrito que[..] ba de titulo".

39 Este topónimo puede interpretarse como 'Cerro del panal de árbol'. Coincide con los trasuntos que únicamente mencionan la traducción: "monte que llaman del panal" (T-NL) y "monte que llaman de el pan[..]” (T-BNAH, dañado en el lugar donde va el último término). 
reyes — también referidos como valientes — se retiraron primero a Thicuintzequaro (territorio de Xaraquaro) y enseguida regresaron con la leña hurtada. ${ }^{40}$ Fueron perseguidos en balsas de rama por los valientes de Pareo quienes los querían matar, por lo que los tres hermanos, don Francisco Tsintsicha, Tsitsispahndaquare y Tariacuri, usaron la onda para defenderse: después únicamente se quedaron tres habitantes en Pareo, en calidad de prisioneros y convertidos en esclavos (pacumunscata) de los chichimecas uacúsecha. Según los trasuntos, los reyes mataron a los atacantes quienes son descritos como "los valientes defensores de la leña", quedando dos (versión T-BNAH) o tres sobrevivientes (versión T-NL) en el mencionado pueblo, aunque no se menciona su posición subyugada.

Posteriormente, el rey don Francisco Tsintsicha navegó en canoa a Toquaro donde construyó una yácata y tomó posesión de la tierra, haciendo el siguiente recorrido: empezó en Ychachuen (Ichahchuen en T-BNAH, Ichalchuen en T-NL), Arataro (Joio en T-BNAH, Joro en T-NL) y Huringuequaro (Temascal en ambos trasuntos), donde existe como señal una piedra (de gran tamaño según los trasuntos) que lleva una cruz. ${ }^{41}$ Posteriormente se trasladó a Thincuintzequaro, donde hay una señal de cuatro piedras, dos rojas (los trasuntos hablan de coloradas) y dos verdes (identificadas en los trasuntos como azules renegridas). ${ }^{42}$ Terminó en una isla pequeña (capi omequaro en tarasco), en un puesto llamado Ychachutiro (la parte baja de un lugar alargado) donde existe una señal: allí hay un peñasco grande en la orilla del cerro. También en los trasuntos se menciona una islita pero se agregan los términos en lengua indígena a manera de nombre de lugar: "çapiomequaro" (T-BNAH) y "Sapocomecuaro" (T-NL). En este caso hablan de una piedra grande y especifican que la mojonera está ubicada en el camino a la entrada del monte, omitiendo el topónimo: no obstante, como veremos, más adelante sí aparece como Ichachutiro, en el contexto de los mismos linderos.

En la versión en tarasco se especifica que don Francisco Tsintsicha tiene dominio sobre estas tierras y que él mismo hizo el título para que no se escribieran mentiras, para que todos ellos — pobrecillos — trabajaran las tierras con él y para que siempre se protegieran estas posesiones. Además, se expresa el deseo de que en el futuro todas las personas

${ }^{40}$ En los trasuntos, Thicuintzequaro aparece como Thinguintzequaro (T-BNAH) e Huinguintzequaro (T-NL).

41 El Diccionario Grande de la Lengua de Michoacán (1991 II: 259) contiene la entrada "Huringuequaro. En el baño." (lugar del baño). Palabras y expresiones relacionadas como "Huringuequa curingani. Caldear el horno." indican que se trataba de un baño de agua caliente, llamado temazcalli en lengua náhuatl: este último término rápidamente se hispanizó a temazcal y sigue utilizándose en todo México hasta hoy día.

${ }^{42}$ Probablemente el Thincuintzequaro sea el mismo lugar que el arriba mencionado Thicuintzequaro. En los trasuntos viene escrito como Thinguint[.] quaro (T-BNAH) y Tinguentzequaro (T-NL). 
se amen unas a otras (es decir, que vivan en paz), terminando con la observación de que así acostumbran hablar los monarcas de Toquaro. Cabe agregar que la especificación del objetivo del título se expresa como si fueran las palabras del propio Tsintsicha (las oraciones están en primera persona singular).

En los trasuntos se usa la tercera persona singular para describir los sucesos y se señala que don Francisco era el rey de Toquaro y se separó las tierras desde el primer hasta el último sitio, aunque llama la atención que el lugar inicial es referido como Ichahchutiro en vez de Ychachuen. ${ }^{43}$ Igualmente se aclara que el escrito se hizo para conservar la verdad con el tiempo, para que los hermanos y parientes del gobernante lo mostraran y se defendieran, y que se amaran y tuvieran paz. Los últimos comentarios sobre la defensa y la harmonía de la vida vienen en primera persona singular, como si fueran las palabras exactas del propio rey. Aquí concluye el trasunto de la BNAH, mientras que en el trasunto publicado por León se agrega la fecha 7 de agosto de 1615. Esta podría referir al supuesto momento de elaboración de la traducción, de la copia de una traducción ya existente 0 incluso a la realización del texto original en lengua tarasca: como señalamos arriba, el documento en idioma nativo incluye algunos elementos ortográficos que se presentan precisamente a partir del siglo xviI.

El título en tarasco continúa con las andanzas del rey don Francisco Tariacuri quien se fue (probablemente desde Thicuintzequaro) a Cuirinquaro (Cuirínguaro/Curínguaro) donde tenía a sus valientes labradores (cultivadores de tierras) y donde se anunció que éstos querían destruir al gran pueblo de Pahzquaro (Pátzcuaro), por lo que los reyes siuini ('remolino') empezaron a irse muy satisfechos. ${ }^{44}$ Dos personas rapadas (tal vez se trate de estos monarcas o de algunos de sus guerreros) se subieron al cerro de Thiuapu, en un lugar que se llama Echuhueni. También llegaron los valientes de Cuirinquaro para meterse al pueblo enemigo y antes de medio día todos los habitantes de Pahzquaro murieron a consecuencia de los ataques. De regreso a su lugar de origen, le informaron al rey don Francisco Tariacuri sobre lo sucedido y éste se puso muy contento. El gobernante les sirvió una comida y ellos le dijeron que no comían estos brazos gordos (que aparentemente se les había ofrecido) sino conejos, venados, culebras y codornices (igual que el rey Tsivanqua). Le dijeron a Tariacuri que no se afligiera, que su linaje (probablemente se esté refiriendo al de ambos) era valiente y que por lo tanto vinieron a proteger al rey, con un

43 Véase arriba el itinerario por las diversas mojoneras que coincide con la versión tarasca y ambos trasuntos.

${ }^{44}$ Aunque se optó por interpretar los términos quahngari tharenpohcha como 'valientes labradores', tampoco se puede descartar que el último sea más bien un nombre personal y que deberíamos traducir 'valiente Tharenpohcha'. 
grupo de valientes (todo redactado en primera persona plural). Agregaron que así era su palabra (su discurso) y que los otros (los enemigos) se quedaron mudos. ${ }^{45}$ Luego regresaron (a su lugar de origen) y continuaron peleando para el beneficio de los monarcas (todo escrito en tercera persona plural). La sección final del manuscrito se encuentra destruida y sobrevive únicamente un pequeño fragmento que apenas nos permite identificar su contenido general: trataba de la llegada de los españoles a la ciudad de México en 1519 y al parecer también incluía referencias a Tzintzuntzan, a reyes que se juntaron y otros que se murieron, así como personas que se escondieron por el camino. ${ }^{46}$ Probablemente se trataba de la conquista de Michoacán y el inicio de la evangelización. ${ }^{47}$

\section{Análisis}

Al igual que otros títulos primordiales del centro de Michoacán (Roskamp, 2010), en especial los de Carapan (Roskamp 2003), el ejemplar de Tócuaro se remite extensamente al linaje chichimeca uacúsecha de Tzintzuntzan que hacia finales del siglo xv y principios del siglo XVI había logrado dominar la región por medio de conquistas y alianzas matrimoniales. Su memoria oficial era conservada y transmitida en el discurso del petamuti (sacerdote mayor) que se presentaba anualmente, tanto en la capital como en los pueblos sujetos, durante la fiesta de Equata Cónsquaro, cuando se impartía la justicia general: se trataba de un ritual de Estado que servía para explicar, legitimar y afianzar el poder de la clase gobernante. Una versión tardía y extensa de la mencionada plática, seguramente influenciada por la nueva coyuntura ocasionada por la llegada de los españoles, quedó registrada en la Relación de Michoacán (1539-1541), escrita por el franciscano Jerónimo de Alcalá. Referencias al pasado de los chichimecas uacúsecha fueron también incluidas en otros documentos más breves de mediados y fines del siglo xvi, además de que fueron transmitidas de manera oral (Roskamp, 2002, 2012 y 2013) e incluso aparecieron en los mencionados títulos de la Colonia más tardía. La comparación de las diversas fuentes muestra tanto coincidencias como contradicciones, mostrando que el proceso de trans-

45 Una referencia a los enemigos derrotados como los que no hablan (se quedan mudos) también aparece en un documento tarasco de 1543 que trata de una conquista de Tzintzuntzan, ocurrida en la época prehispánica a raíz de una alianza entre los uacúsecha y un grupo de nahuas (Monzón, Roskamp y Warren, 2009: 27-28, 32-33, frase 9).

${ }^{46}$ Faltan la mitad derecha y la sección inferior de la foja, por lo que solamente se conserva una cuarta parte de la misma.

${ }^{47}$ Se trata de un tema muy común en los títulos primordiales, incluyendo las variantes de Michoacán (Roskamp, 2016). 
misión de las visiones del pasado era dinámico e implicaba tanto la pervivencia como la pérdida, reinterpretación e incluso (re)invención de diversos componentes (Roskamp, 2015 y 2016).

El título primordial de Tócuaro enfatiza el papel del rey Tsivanqua y hace mención de sus tres hijos: los reyes Tsintsicha, Tsitsispahndaquare y Tariacuri, nacidos en Jarácuaro. Salvo Tsitsispahndaquare, todos también son referidos con el término honorífico en español y un nombre cristiano: don Antonio Tsivanqua, don Francisco Tsintsicha y don Francisco Tariacuri. Al comparar los antropónimos con la información genealógica que proporciona la Relación de Michoacán (Alcalá, 2000), ${ }^{48}$ podemos identificarlos como Zizispandaquare, Zuangua, Zinzicha (también llamado Tangaxoan) y Tariacuri: los primeros tres fueron los últimos reyes del reino tarasco (en este orden) y el cuarto fue descendiente colonial y gobernador indio de la ciudad y provincia de Michoacán entre 1543 y 1545 (López Sarrelangue, 1965: 169-172). ${ }^{49}$ No obstante, al mismo tiempo el nombre Tariacuri también parece referir a un antepasado homónimo, primo-tío-abuelo de Zizispandaquare, que resulta ser el héroe de la historia narrada por el petamuti: hijo de una señora de Jarácuaro, fue fundador de la triple alianza Tzintzuntzan-Ihuatzio-Pátzcuaro y sembró los cimientos del posterior reino tarasco (Alcalá, 2000: 372-519). De esta manera, dos personajes con el mismo nombre que vivieron en épocas distintas, en el título llegaron a ser interpretados como uno solo..$^{50}$ En cuanto a los nombres cristianos de los reyes, se debe señalar que Zuangua murió en 1520 (Warren, 1989:29), es decir antes de la conquista española de Michoacán, y nunca fue bautizado. El hecho de que en el texto se le identifique como don Antonio, podría indicar que fue confundido con otro personaje, ya que se trata del nombre bautismal de Huitzimengari, hermano menor de Francisco Tariacuri y su sucesor en el gobierno de la ciudad y provincia de Michoacán entre 1545 y 1562 (López Sarrelangue, 1965: 172-178). Cuando se hizo el documento de Tócuaro, al parecer ya se había confundido tanto la relación de parentesco entre estos nobles, como

48 En el presente texto empleamos una edición publicada en 2000. La transcripción de la fuente se encuentra disponible también en línea (www.colmich.edu.mx), junto con un buscador que proporciona acceso a excelentes resúmenes sobre lugares, personajes, dioses y categorías sociales mencionados en el texto (véase también Espejel Carbajal, 2008).

49 Teniendo en cuenta las diferentes grafías de estos antropónimos en la documentación colonial, optamos por emplear las que aparecen en la Relación de Michoacán.

${ }^{50}$ Este proceso no es exclusivo de la documentación tardía sino es común en las tradiciones históricas de los indígenas mesoamericanos. Véase por ejemplo como la información sobre el gobernante Cosijoeza de los Bènizàa de 0axaca en realidad recoge datos asociados con cuatro personajes homónimos que vivieron entre los siglos XIV y XVI: algo semejante ocurrió en el caso del gobernante Cosijopii (Oudijk, 2000: 34-42, 231). 
su ubicación en el tiempo: se trata de una característica encontrada también en otros títulos de la época colonial tardía (Roskamp, 2010: 41, 43-46).

El ejemplar estudiado resalta que Zuangua arribó a la isla de Jarácuaro tras una peregrinación que partió desde más allá de Guayángareo y pasó por Xénguaro, Cutzaro,Tzintzuntzan y la isla de Janitzio: su hijo Zinzicha después se trasladó a Tócuaro (véase también el mapa 1). El tema de la migración hace pensar en el discurso del petamuti (Relacion de Michoacán) en que se cuenta como el padre fundador del linaje en el poder, Hireti o Uacús thicatame, llegó a la región de Zacapu y sus descendientes continuaron hacia el lago pasando por diversos lugares para finalmente asentarse en Pátzcuaro. En este caso, el itinerario tomó mayor tiempo e implicó la participación de diversos líderes sucesivos, mientras que la variante mencionada en el título únicamente involucra a dos generaciones. Además, en la versión del sacerdote mayor, los migrantes chichimeca uacúsecha llegaron desde el norte mientras que según el título vinieron del oriente. ${ }^{51}$

La inclusión de Guayángareo probablemente obedezca en primer lugar a que esta ciudad, rebautizada como Valladolid, se convirtió en la sede de las autoridades civiles y eclesiásticas de la provincia y obispado de Michoacán a partir de 1580 (Herrejón Peredo, 2000: 183), a costas de Pátzcuaro que por su parte había desplazado a Tzintzuntzan, por lo que resulta evidente que el documento en cuestión fue elaborado después del mencionado año. ${ }^{52}$ Cabe agregar que a Guayángareo al parecer no se le daba importancia en el discurso del petamuti (por lo menos no en la versión registrada en la Relación de Michoacán) ya que es mencionado una sola vez en el contexto de una campaña militar del señor Chapa de Curínguaro que inició en Xénguaro y terminó en Araro, en la orilla oriental del Lago de Cuitzeo (Alcalá, 2000: 461) ${ }^{53}$ Este Xénguaro también aparece como Xénguaran y tenía mayor relevancia ya que brevemente fue la sede del dios solar Curicaueri cuando los chichimecas uacúsecha Pauacume y Vapeani tuvieron que abandonar Guayameo (Santa Fe de la Laguna) a raíz de un importante agüero (ibid., 352). Tiempo después adquirió un papel en el control de la parte norte de la región cuando Hiripan, Tangaxoan e Hiquingaje instalaron uno de sus caciques en el lugar (ibid., 523). No sa-

${ }^{51}$ El tema de los traslados poblacionales en el contexto de la fundación de pueblos tenía mucha importancia en las tradiciones históricas de los grupos mesoamericanos y sus descendientes coloniales. En el caso michoacano también podríamos agregar los casos del antiguo Jicalán (Roskamp, 1998: 81-195) y Tetlama (Carrasco, 1969).

${ }^{52}$ El hecho de que el título en tarasco conserva el antiguo nombre, quizá sea indicación de que éste seguía teniendo mucha presencia entre los habitantes indígenas de la región, a pesar de que oficialmente la ciudad ya era llamada Valladolid, término español que se usa en las dos traducciones del documento.

53 Es importante observar que en la misma fuente el topónimo también aparece escrito como Cuirynguaro, entre otras variaciones. 
bemos si la incorporación de Xénguaro al título de Tócuaro tenga que ver con su antiguo estatus: debemos tener en cuenta que se ubica precisamente a la mitad del camino de Guayángareo a Cutzaro, pueblo ubicado en la orilla noroeste del Lago de Pátzcuaro. En este sentido tanto Xénguaro como Cutzaro podrían haber fungido sobre todo como marcadores de la ruta. ${ }^{54}$ Cutzaro no aparece en la Relación de Michoacán pero se encontraba muy cerca del ya mencionado Guayameo (Santa Fe), el primer lugar de la ribera donde los chichimecas uacúsecha arribaron y residieron durante un largo periodo (cinco generaciones sucesivas). El asentamiento ocupaba un sitio estratégico donde se juntaba el camino que venía de Pátzcuaro y Tzintzuntzan con el trayecto Guayángareo-Zacapu. ${ }^{55}$

La mención de Tzintzuntzan en el texto de Tócuaro no es sorprendente ya que constituye un importante referente en muchos otros títulos de la región, por tratarse de la antigua capital del reino tarasco y sede de los supremos señores chichimeca uacúsecha, desde el gobierno del rey Zizispandaquare hasta la última etapa de la gestión de don Pedro Cuiniharángari como gobernador indio de la provincia de Michoacán: en 1538 perdió su estatus a favor de Pátzcuaro. ${ }^{56}$ Janitzio y Jarácuaro son las últimas islas que se encuentran en la ruta acuática de Tzintzuntzan a Tócuaro, en la orilla suroeste del lago: cabe agregar que el transporte de personas y productos en diversos tipos de canoa entre las poblaciones lacustres era muy importante en las épocas prehispánica y colonial. ${ }^{57}$ Más adelante veremos que Jarácuaro ocupa un lugar trascendente en la versión de la historia chichimeca uacúsecha que fue narrada por el petamuti y registrada por el franciscano Alcalá. ${ }^{58}$

Según el título, el rey Zuangua realizó diversas acciones durante su traslado a Tócuaro. Al mencionar que hizo volar a los colibríes en las yácatas de Tzintzuntzan, se está refiriendo al significado del propio topónimo: 'lugar de colibríes'. Aunque podría ser una

${ }^{54}$ Hoy día constituye parte de la importante carretera federal 15 que viene desde México, pasa por Morelia (la antigua Valladolid) y la mencionada laguna, para seguir rumbo a Zacapu y Guadalajara.

55 Con la fundación del pueblo-hospital de Santa Fe de la Laguna cerca del antiguo Guayameo (en 1533), se originó un pleito con Cutzaro sobre la posesión de ciertas tierras y aguas: hoy día los mismos recursos siguen siendo motivo de conflicto entre Santa Fe y Quiroga, pueblo que llegó a incorporar tanto a Cutzaro como a Cocupao (Roskamp, 2011a).

${ }^{56}$ El cambio fue motivo de una larga lucha por parte de diversas facciones y autoridades tzintzuntzeñas para recuperar sus antiguos privilegios. Variantes de sus discursos sobre el glorioso pasado prehispánico y colonial temprano quedaron expresadas en una serie de pinturas y textos en escritura alfabética (Roskamp, 1997, 2002, 2012 y 2013; Monzón, Roskamp y Warren, 2009).

${ }^{57}$ Por ejemplo, en el Lienzo de Jucutacato o Lienzo de Jicalán (aprox. 1565), se resalta la función clave de Erongaricuaro, localizado en la orilla occidental de la laguna, para traslados en canoa de personas y tributos a Tzintzuntzan, Ihuatzio y Pátzcuaro (Roskamp, 1998: 151-152; 2001: 129).

${ }^{58}$ Janitzio solamente es mencionado una vez (Xanecho) como lugar donde el rey Zuangua guardaba una cantidad considerable de plata que formaba parte de su tesoro (Alcalá, 2000: 671). 
simple explicación y reafirmación del nombre, ${ }^{59}$ tampoco se puede descartar que sea una referencia a un ritual de fundación y toma de posesión del lugar en cuestión por parte del gobernante. ${ }^{60}$ Esta última interpretación cobra importancia al considerar otros acontecimientos ocurridos en el camino. Al llegar a Xénguaro, Zuangua llegó a las yácatas y clavó una flecha en la tierra para apropiarse del lugar, mientras que en la isla de Janitzio colocó un total de cinco: tres en unas fogatas y dos en el suelo. Aunque el texto tarasco no dice nada al respecto, vimos que los dos trasuntos agregan que el rey también empleaba cuatro flechas para marcar los límites de su territorio en Jarácuaro. Esta señalización de límites territoriales y toma de posesión mediante la colocación de flechas por parte de los reyes chichimeca uacúsecha, también son mencionadas en otros títulos primordiales de la región, como los de Nahuatzen y Carapan, entre otros (Roskamp, 2003 y 2004). ${ }^{61}$ Según el amplio corpus documental de este último pueblo, el mismo proyectil incluso sirvió para crear diversos ojos de agua (al perforar la tierra) y figura como cetro de uno de los reyes, si bien en la mayoría de las representaciones de los gobernantes indígenas aparece en combinación con el arco y el carcaj o aljaba (Roskamp, 1998: 214-217, 2003: $315)^{62}$

En el título de Tócuaro se enfatiza que el arco y el carcaj de flechas fueron enviados al rey Zuangua para que buscara comida, cazando conejos, venados, culebras y codornices: también recibió un bezote y un collar hechos de oro, además de que fue instruido a vestirse únicamente con un cuero. ${ }^{63}$ Efectivamente parece tratarse de la toma de posesión de un rey, como acertadamente apuntan los dos trasuntos: ninguna versión aclara de dónde

${ }^{59}$ Una representación gráfica de colibríes volando encima de una fuente de agua, forma parte de un escudo de armas de Tzintzuntzan, elaborado hacia fines del siglo xvI (Roskamp, 2002: 247).

${ }^{60}$ En el Lienzo de Jucutacato aparece la migración de los nahuas que fundaron Jicalán, siendo guiados por su dios Tezcatlipoca en forma de un águila. Antes de llegar a su destino, también pasaron por Tenochtitlan, donde la mencionada ave sagrada se paró encima de un nopal para expresar el significado del topónimo y a la vez remitir al acto de fundación por los mexica (Roskamp, 1998: 125). Para mayor información sobre mitos de origen en el contexto michoacano, incluyendo comparaciones con el centro de México, véase Roskamp (2010).

${ }^{61}$ Mientras que en la narración de Tócuaro las flechas se encontraban al lado de las yácatas, en uno de los manuscritos pictográficos de Carapan el proyectil parece atravesar la pirámide (Roskamp, 2000: 163-164), aunque también existe la posibilidad de que esté colocado enfrente de este edificio.

${ }^{62}$ En dos lienzos pertenecientes al mismo conjunto, también se pintó a Margarita de Austria, reina de España y esposa de Felipe III, con un atado de flechas cruzadas en su mano como símbolo de poder (Roskamp, 2003: 339-342).

${ }^{63}$ Las representaciones de los reyes en otros títulos también enfatizan el arco y las flechas, mientras que los demás atributos varían. En los títulos de Carapan, Nahuatzen y Puácuaro, por ejemplo, se omiten referencias a los bezotes. 
vinieron los atributos y mandamientos. El episodio hace pensar en diversos elementos de la antigua narración del petamuti que forma parte de la Relación de Michoacán. Cuando Hireti Ticátame, el fundador del linaje de los reyes chichimeca uacúsecha, llegó al norte de Michoacán y estableció una alianza matrimonial con los pobladores locales de Naranjan, supuestamente dio un discurso en que resaltaba sus obligaciones: visitar a los dioses de los cerros, traer leña para los fogones y hacer flechas para la caza de venados, como ofrendas a las deidades. Aclaraba que las pieles servían como mantas en primer lugar para envolver al dios solar Curicaueri pero también para arropar al propio gobernante: la carne servía el mismo doble propósito en el ámbito de la alimentación. ${ }^{64}$ Esta importante costumbre también aparece asociada a Vápeani y Tariacuri, y seguramente la practicaban todos los demás miembros supremos del linaje (Alcalá, 2000: 342-343, 354355, 405-406, 473-475): claramente marca la identidad chichimeca de los uacúsecha quienes según sus propias narrativas (en especial el discurso del petamuti) pertenecían a una tradición nórdica de cazadores. ${ }^{65}$

Aunque la flecha, a veces sola (a manera de cetro) pero generalmente acompañada por el arco y la mencionada funda, remite a la autoridad e identidad chichimeca de su portador, la misma Relación de Michoacán muestra que tenía significados adicionales (aunque todos relacionados entre sí). En primer lugar jugaba un papel fundamental como arma en las guerras que se llevaban a cabo en nombre de las deidades y en especial del dios patrono Curicaueri: incluso se consideraba una representación e instrumento de esta divinidad principal (Alcalá, 2000: 472). Al sitiar asentamientos enemigos, el rey Tariacuri hacía hogueras alrededor de sus asentamientos y encima de cada una se clavaba una flecha, "que era señal de guerra" (ibid., 374). En otra ocasión, las acciones militares fueron anunciadas mediante el envío de un manojo de flechas al adversario por parte del mismo señor uacúsecha (ibid., 430). La flecha podía también simbolizar la toma de posesión de un señorío: cuando Tariacuri anunció y encargó la fundación de la triple alianza michoacana (Ihuatzio-Tzintzuntzan-Pátzquaro) a sus sucesores, hizo tres montones de tierra y en cada uno puso una piedra y una flecha (ibid., 513-516). En este contexto, los proyectiles podrían aludir también a las posteriores conquistas con que se concretizó

\footnotetext{
${ }^{64}$ Las envolturas son conocidas como bultos sagrados o vingacuriri y jugaban un papel clave en los cultos religiosos y la veneración de los antepasados (Roskamp, 2010).

${ }^{65}$ En otras partes de la misma fuente se documenta que las uñas del venado eran atadas a las piernas de los gobernantes uacúsecha quienes también se colocaban una guirnalda de cuero (ibid., 368, 632). Buenas imágenes de la indumentaria completa se encuentran en la Relación de Michoacán (ibid., 629, 665) y el primer escudo de armas de Tzintzuntzan (Roskamp, 2002: 238, 241-244). Para un análisis sobre la importancia del venado en la cultura tarasca, véase Faugère Kalfon (1998).
} 
el plan y que llevaron a la creación del gran reino tarasco (ibid., 516-525) ${ }^{66}$ Asimismo, la impartición de justicia a los transgresores de la ley se llevaba a cabo durante una fiesta que se llamaba "de las flechas" (ibid., 333-340): se trataba de un importante ritual de Estado en que el petamuti contaba la historia de la creación del reino y del grupo en el poder para legitimar y fortalecer el status quo existente (Roskamp, 2000: 256). Lo anterior muestra que la presencia de la flecha, en forma individual o en manojo, clavada en la tierra o en manos de algún personaje, simboliza el poder y dominio de los chichimecas uacúsecha y de su dios tutelar Curicaueri.

Según la Relación de Michoacán, las "insignias de señor" eran el bezote, orejeras y brazaletes, todos de oro, así como collares de turquesa. ${ }^{67}$ No solamente fueron usadas por los reyes sino que éstos también las otorgaban, en ceremonias especiales de toma de posesión, a los señores de los pueblos que eran sus súbditos. Implicaban lealtad y servicio hacia el gobernante supremo, el dios solar Curicaueri y las demás deidades, con especial énfasis en el desempeño militar: las personas que ostentaban las insignias eran "valientes hombres", llamados quangáriecha en lengua tarasca (Alcalá, 2000: 563). ${ }^{68}$ Otra fuente, el diccionario de Lagunas (1574), incluye la palabra angamecha que se refiere a quienes tenían puesta la angamequa o 'bezote'. ${ }^{69}$ Vimos que en el título de Tócuaro se menciona el bezote del rey Zuangua y se le agrega el adjetivo "valiente", término que también es usado múltiples veces en los títulos primordiales de Carapan y el ejemplar de Nahuatzen. ${ }^{70}$ En cuanto al collar, otra de las insignias, llama la atención que según el documento tocuarense era de oro mientras que de acuerdo a la Relación de Michoacán

${ }^{66}$ Cabe agregar que las tres flechas únicamente son mencionadas en el texto y que fueron omitidas en la lámina correspondiente a este episodio de la narración.

${ }^{67}$ Si bien en la mayoría de las referencias a los bezotes se resalta que eran de oro, también había ejemplares de turquesa.

${ }^{68}$ El Diccionario Grande de la Lengua de Michoacán (1991) contiene las entradas "Qhuangari. Valiente." y "Qhuangariecha. Valientes.". Resulta interesante que el término fue también empleado para la estrella de la mañana, es decir Venus, deidad muy cercana a Curicaueri (Monzón, 2005: 145-146; Beltrán, 2012: 57).

69 "Angamecha, los que tenian beçotes entre la barba y el labio. Angameni, estar de pies en el agua, o poner los tales beçotes, que el Rey ponia a los señores y valientes en la guerra, señalandolos con esta hydalguia, quasi por sustento, pilar, fauor y amparo de la otra gente plebeya. Y assi los tales podian tambien interceder, induzir, importunar y boluer por ellos como. Angandahpeni, Hazer lo sobredicho." (Lagunas, 1983: 221-222). En el Diccionario Grande de la Lengua de Michoacán (1991) encontramos "Angameni. Tener beçotes." y "Beçotes. Angamequa.".

${ }^{70}$ Como se dijo arriba, en los últimos documentos no aparece el bezote. Resulta interesante ver que según el documento tarasco de Tócuaro (párrafos 4 y 7), los valientes también eran llamados andumucha, "los honrados" (los que adquirieron honra/méritos). 
se elaboraba con turquesa. No obstante, en esta última fuente también se menciona "una argolla de oro" guardada en el arca de Curicaueri (Alcalá, 2000: 349). ${ }^{71}$ Cabe agregar que el oro era considerado excremento de la misma deidad solar y que cualquier artefacto de este material (bezote, brazalete, orejera y collar) refería al poder sagrado (Roskamp, 2010: 70). ${ }^{72}$

El título de Tócuaro enfatiza el estatus de Jarácuaro como sede de los reyes chichimeca uacúsecha: Zuangua lo tomó en posesión, allí nacieron sus hijos Zinzicha, Zizispandaquare y Tariacuri, y fue punto de partida para una incursión a Pareo y la posterior fundación de Tócuaro. Como señalamos líneas arriba, el discurso del petamuti en la Relación de Michoacán resalta la importancia de este pueblo isleño: la fuente nos muestra que su estrecha relación con los gobernantes chichimeca uacúsecha fue compleja, alternándose diversas uniones y conflictos que también involucran a Curínguaro y Pátzcuaro. Una alianza inicial se estableció cuando, antes de asentarse en este último pueblo, Pauacume y Vapeani se dieron cuenta de que los habitantes de Jarácuaro eran sus parientes: el primero se casó con la hija de un pescador de la isla y ambos procrearon un hijo llamado Tariacuri, el héroe de la narración, quien nació en el mencionado pueblo (Alcalá, 2000: 372) o en un barrio de Pátzcuaro llamado Tarimichundiro (ibid., 357). Los señores de la laguna ofrecieron sus hijas a los dos hermanos e incluso les otorgaron cargos prestigiosos de sacrificador y sacerdote (ibid., 361).

El acercamiento entre los isleños y los chichimecas uacúsecha provocó el enojo del gobernante de Curínguaro, al parecer una entidad muy poderosa en la región, quien mandó matar a los hermanos después de que había logrado que su contraparte de Jarácuaro los expulsara de la laguna (ibid., 367-371). Tiempo después, Tariacuri quiso vengar la muerte de su padre y tío, haciendo señales de guerra a lo largo de la ribera del lago para que sus enemigos huyeran a la isla, impidiendo que siguieran laborando sus parcelas en tierra firme y juntando leña en los montes cercanos: incluso se fueron los habitantes de Pareo, levantando espuma cuando se metieron a la laguna (ibid., 372-375). ${ }^{73}$ Los de Pareo compartían un origen común con los chichimecas uacúsecha porque estuvieron juntos en Guayameo antes del ya mencionado agüero que causó la división de diver-

${ }^{71}$ Según Covarrubias (1995: 116), una argolla es un círculo de hierro u oro que traían al cuello.

72 Navarrete (2011: 24) proporciona una lista de "bienes culturales chichimecas" para los grupos indígenas del centro de México: buena parte de ellos coincide con las características culturales e identitarias que mencionamos en el caso de los chichimecas uacúsecha.

73 El texto de la Relación de Michoacán menciona que prendió fuegos grandes que producían mucho humo. En una lámina se muestra que también colocó una flecha al lado, que como vimos constituye una señal de guerra (Alcalá, 2000: 377). 
sos grupos que se establecieron en diferentes lugares con sus respectivos dioses. Además, tenían un gran tianguis al que también acudían los isleños de Jarácuaro (ibid., 398).

Cuando los isleños quisieron romper el cerco de los chichimecas uacúsecha, buscando apoyo de sus aliados de Curínguaro y Tariaran, Tariacuri fue informado sobre las intenciones en su contra y mandó matar al sacerdote enemigo encargado de la estrategia y movilización de las tropas: el cuerpo de la víctima fue cocido para mandar la carne a los señores de los tres pueblos enemigos a quienes dijeron que pertenecía a un esclavo sacrificado de Tariacuri (ibid., 376-394). El autor del engaño tuvo que huir de regreso a Pátzcuaro cuando el gobernante de Tariaran, al darse cuenta de la verdadera procedencia del alimento, inició una persecución y destruyó sus casas. Un nuevo enfrentamiento ocurrió cuando un primo de Tariacuri tuvo relaciones con una mujer del señor de Jarácuaro, a quien llegó a conocer en el mercado de Pareo, lo que le costó la vida no solamente a él sino también a sus hermanas (ibid., 394-400).

Ante las hostilidades, Tariacuri planeaba ir a Condémbaro para pedir ayuda, lo que implicaba cruzar por el territorio del gobernante de Curínguaro, a quien tuvo que pedir permiso. El último lo convenció de quedarse en uno de los pueblos bajo su mando (probablemente en Tupátaro) y más tarde incluso le ofreció una de sus hijas para que se casara con ella: de la unión nació un hijo llamado Curátame. Cabe agregar que de acuerdo al discurso del petamuti, los habitantes de Curínguaro eran sobre todo agricultores, aunque también se resalta la presencia de "valientes hombres", es decir guerreros nobles (ibid., 370). Igual que los de Pareo, habían estado en Guayameo antes del multireferido agüero: no obstante, llama la atención que cuando Tariacuri les trajo un venado para hacer una comida, no lo sabían desollar ni preparar (ibid., 404-405), sugiriendo que no compartían este conocimiento y rasgo clave de la identidad chichimeca uacúsecha.

Cuando su esposa no cumplió con sus deberes y además le fue infiel, Tariacuri volvió a casarse con mujeres de otro pueblo pero tuvo que huir ante los ataques y persecuciones de su primer suegro de Curínguaro quien se enojó por los nuevos enlaces matrimoniales (ibid., 400-435). Entre tanto, Pátzcuaro, la sede original de Tariacuri, había sido invadida por ejércitos de Jarácuaro, Curínguaro y Tariaran, quienes al parecer se disputaban el lugar. A raíz del conflicto, los isleños, que igualmente experimentaban tensiones entre sí, se dirigieron a Tariacuri y le solicitaron que regresara a tomar el control:

Pues vino Taríacuri con su gente al monte llamado Arízizinda, monte de Pázquaro. Y a la media noche empienza a tocar su silbatillo encima del monte, que contrahacía las águilas; y oyeron aquellos silbos a la media noche los de Curýnguaro que tenían el asiento de Pázcuaro y levantáronse todos y fuéronse a su pueblo con gran polvareda que iban levantando; y los 
isleños se entraron en la laguna, que hacían espuma al entrar; y los de Taríaran se fueron también a su pueblo y iban haciendo polvareda, huyendo. Y volvióse Taríacuri a su asiento de Pázquaro, con su gente (ibid., 434-436).

Enseguida, Tariacuri inició la búsqueda de sus dos sobrinos y futuros sucesores, Hiripan y Tangaxoan, quienes se habían perdido durante los enfrentamientos con los enemigos de los chichimecas uacúsecha. Luego de deambular por la Sierra Tarasca, incluyendo al pueblo de Sauinan (Sevina), ambos finalmente reaparecieron en Pareo donde fueron atendidos por otro de sus familiares que vivía allí (ibid., 436-447).

En un momento posterior, Tariacuri abandonó Pátzcuaro para dejarlo a cargo de su hijo Curatame quien previamente había permanecido en Curínguaro y con quien mantuvo una relación conflictiva: tiempo después mandó asesinar a su vástago y retornó a su sede original (ibid., 447-452, 489-494). Mantuvo vigilada la isla de Xaracuaro y los de Curinguaro seguían siendo sus principales enemigos (ibid., 468-473). Después fundó una triple alianza compuesta por Tzintzuntzan, Ihuatzio y Pátzcuaro, siendo gobernados respectivamente por sus dos sobrinos preferidos e Hiquingaje, otro de sus hijos. Los últimos conquistaron muchos pueblos en la región, incluyendo Curínguaro, y de esta manera construyeron un gran reino (ibid., 513-525). Jarácuaro también vino a quedar bajo su control, probablemente en la fase inicial de las campañas militares (ibid., 610), ya que según el relato una facción de los isleños tuvo una participación muy activa en la expansión de los dominios de los chichimecas uacúsecha, aunque seguían siendo sus súbditos (ibid., 468, 471, 512, 517, 523-524). ${ }^{74}$

Durante un tiempo Ihuatzio lideró la triple alianza e Hiripan, su señor, incluso eliminó el linaje gobernante de Pátzcuaro. En las últimas décadas del siglo xv, a partir del gobierno de Zizispandaquare (hijo de Tangaxoan I), Tzintzuntzan adquirió mayor poder y se convirtió en la capital del reino (ibid., 541-543), episodio sobre el cual la narrativa del petamuti no proporciona mayor información. ${ }^{75}$ Sin embargo, Pátzcuaro mantuvo peso como centro religioso y a partir de 1538, ya bajo el yugo español, llegó a ser la ciudad más importante de la provincia novohispana de Michoacán, sede de las autoridades

${ }^{74}$ Para referirse a los conquistados y los siervos, es decir quienes servían a los señores en el poder, en el relato a menudo se emplea el término esclavo, también usado para designar a los isleños (ibid., 610).

75 Según la lectura de un antiguo códice guardado en Tzintzuntzan hacia 1543, la ocupación del lugar por los chichimecas uacúsecha efectivamente se logró en tiempos de Zizispandaquare, pero supuestamente se consiguió a través de las armas, con apoyo de grupos de mercaderes nahuas (Monzón, Roskamp y Warren, 2009). 
españolas e indígenas: esto sucedió cuando don Pedro Cuiniharángari era cacique-gobernador de la mencionada entidad (Martínez Baracs, 2005: 252-267). ${ }^{76}$

El amplio discurso del petamuti resalta como los chichimecas uacúsecha llegaron a dominar los demás pueblos michoacanos mediante alianzas matrimoniales y conquistas militares, un proceso marcado sobre todo por repetidos encuentros y desencuentros con las élites de Jarácuaro y Curínguaro, entre otros. Al realizar la comparación con la narración muy breve en el título de Tócuaro, podemos observar que existen similitudes y diferencias. En primer lugar llama la atención que en ambos discursos se menciona el nacimiento de Tariacuri en Jarácuaro. Sin embargo, en el título este lugar también constituye la sede para otros gobernantes del mismo linaje (como vimos, mencionados de manera incompleta y en orden distinto), contradiciendo la información encontrada en la Relación de Michoacán que asocia los descendientes y sucesores en el gobierno con Pátzcuaro, Ihuatzio y sobre todo con Tzintzuntzan. En segundo lugar resalta que ambos textos se refieren a la relación cercana o incluso alianza entre Tariacuri y los pobladores de Curínguaro. Aunque en la narrativa del petamuti se detalla que se trataba de un enlace matrimonial que funcionó durante un corto tiempo entre largos periodos de enemistad, en el título únicamente se menciona que la unión tuvo fines militares. En tercer lugar se observa que ambos documentos se refieren a una conquista de Pátzcuaro. No obstante, en la Relación de Michoacán se distingue entre una toma del lugar por tropas aliadas de Tariaran, Jarácuaro y Curínguaro, y la posterior derrota de estas fuerzas por Tariacuri quien retomó su antigua sede. En el título se trata de una sola campaña llevada a cabo por Curínguaro pero supervisada o tal vez incluso liderada por Tariacuri. En cuarto lugar se puede mencionar que las dos fuentes enfatizan el dominio de Jarácuaro por los chichimecas uacúsecha: según el título era el centro de poder de donde se emprendieron las demás conquistas mientras que en la narración del petamuti se informa que fue más

${ }^{76}$ Don Pedro, isleño (posiblemente de Jarácuaro) y "hermano adoptivo" del último rey Zinzicha, gobernaba Michoacán entre 1530 y 1543, antes de Francisco Tariacuri y Antonio Huitzimengari (López Sarrelangue, 1965: 55-56, 203-205). En el juicio que llevó a la condena capital de Zinzicha (1530), rindió un testimonio que confirmaba las acusaciones de los españoles (Warren, 1985: 227). Además, como informante principal de fray Jerónimo de Alcalá, consiguió que en la Relación de Michoacán se enfatizara su supuesto liderazgo al momento de la llegada de los conquistadores, logrando un encuentro pacífico y evitando enfrentamientos militares. Sin embargo, otras fuentes un poco más tardías más bien resaltan el papel protagónico del rey tarasco en estos acontecimientos (Roskamp, 1997: 232). Los puntos de vista e intereses personales de Cuiniharángari también podrían estar detrás de la amplia atención que la Relación de Michoacán dedica al papel de los isleños en la consolidación y ampliación del reino tarasco (Espejel Carbajal, 2008, 2: 285). Al parecer don Pedro hábilmente aprovechó las coyunturas cambiantes y alcanzó a mantenerse en la cima del gobierno indígena por poco más de una década (Roskamp, 2011b; Stone, 2004: 154-187; Warren, 1985: 240). 
bien uno de los lugares conquistados, aunque también se aclara que los isleños se aliaron y participaron en las campañas que llevaron a la consolidación y expansión de la triple alianza y del reino. En quinto lugar, tanto el título como el discurso del sacerdote mayor se remiten a la relación cercana entre Jarácuaro y Pareo, aunque difieren en cuanto a su naturaleza. Conforme al primero, los isleños se fueron a Pareo para sacar leña e incluso mataron a sus habitantes y esclavizaron a los pocos sobrevivientes cuando éstos intentaron defender sus recursos. De acuerdo al segundo, los pobladores de Pareo huyeron al lago junto con los isleños cuando Tariacuri sitió a Jarácuaro: sin embargo, en un momento posterior tanto isleños como chichimecas uacúsecha acudían al gran mercado de Pareo y después incluso se refugiaron allí los sobrinos de Tariacuri en la casa de un tío. En sexto lugar, las dos narrativas coinciden en que los habitantes de Jarácuaro tenían que acudir a tierra firme para el abasto de leña, aunque la Relación de Michoacán agrega las tierras de cultivo para los alimentos (omitidos en el título).

El documento de Tócuaro hace mención de reyes siuini ('remolino'), elemento que no podemos identificar en el relato del petamuti. Tal vez sea una referencia a una determinada clase de gobernantes o guerreros. Tampoco se puede excluir la posibilidad de que remita a su lugar de procedencia, que podría ser Sevina, lugar de la Sierra Tarasca, donde deambulaban los sobrinos de Tariacuri antes de terminar en Pareo, como señalamos arriba. Aunque este lugar no tuvo un papel importante en la Relación de Michoacán e incluso solamente es mencionado en dos ocasiones más, ${ }^{77}$ sí figura en los títulos de Carapan como sede de unos reyes que acompañaban a Tariacuri como aliados en las conquistas de los pueblos que no se querían sujetar al poder de los chichimecas uacúsecha (Roskamp, 2003: 317).

Otro elemento interesante en el título es la mención de dos personas rapadas que, como parte de la campaña militar de Curínguaro y de Tariacuri, se acercaron a Pátzcuaro y se subieron al cerro de Thiuapu, llegando a un sitio llamado Echuhueni. Los dos topónimos también aparecen en el discurso del petamuti, como dos lugares donde el padre y tío de Tariacuri cazaban cuando vivían cerca de Pátzcuaro (Alcalá, 2000: 352). ${ }^{78}$ El primero parece tener mayor importancia y es descrito como un montecillo donde Tariacuri explicó a sus sobrinos e hijo la creación de la triple alianza y los planes para la conquista del pueblo enemigo de Tariaran (ibid., 513-515). Con respecto a los dos in-

${ }^{77}$ La primera vez aparece como uno de los pueblos serranos que mantenían conflictos entre sí (Alcalá, 2000: 467) y la segunda como uno de los lugares conquistados por los chichimecas uacúsecha antes de la muerte de Tariacuri (ibid., 519).

78 Es posible que Echuen sea el pueblo que aparece en los antiguos mapas del Lago de Pátzcuaro reproducidos por Eduard Seler (aparece como Echuuen) y fray Pablo Beaumont (escrito como Ychuen). 
dividuos mencionados en el documento de Tócuaro, parece que tuvieron una función especial y llegaron antes que los ejércitos. Probablemente puedan ser identificados como espías que según la Relación de Michoacán eran de alto rango y tenían un papel fundamental en los conflictos militares de carácter tanto ofensivo como defensivo, observando los asentamientos y/o movimientos enemigos desde lo alto de los cerros (ibid., 386, 453, 578 , etc. $)^{79}$

Según el texto de Tócuaro, Tariacuri fue informado sobre la victoria y preparó una comida para los victoriosos quienes rechazaron los alimentos, argumentando que únicamente comían conejos, venados, culebras y codornices, agregando que su anfitrión no se afligiera y que ellos se ponían a su servicio por ser del mismo linaje. A la luz de la información proporcionada por la Relación de Michoacán, se puede comentar lo siguiente. Según esta fuente, la caza y el consumo de estos animales, así como su uso ritual como ofrenda para los dioses (especialmente los venados), formaban una parte esencial de la identidad de los chichimecas uacúsecha. Se resalta además que el compartir alimentos con el pueblo y con otros nobles era considerado un elemento esencial de un buen gobernante (Alcalá, 2000: 602, 604-605) y se destaca su papel en ocasiones importantes: como ejemplos pueden mencionarse el ofrecimiento de carne de venado al pescador durante el primer encuentro entre los chichimecas uacúsecha y los isleños (ibid., 354), la comida que ofreció Tariacuri a los isleños de Cuyumeo (Cuyameo) que después se aliaron con él en las campañas militares (ibid., 473), o el banquete que prepararon para los españoles cuando éstos llegaron a la capital Tzintzuntzan (ibid., 659,670$){ }^{80}$ Con respecto a la relación entre los habitantes de Curínguaro y los chichimecas uacúsecha, vimos que eran parientes y habían estado juntos en Guayameo antes del agüero: Tariacuri incluso era hijo de una mujer de Curínguaro. A pesar de ello, los habitantes de este último pueblo no

${ }^{79}$ En cuanto a la práctica de remover el pelo, llama la atención que los nahuas del centro de México llamaban cuaochpanme ('los rapados') a los tarascos y que en el Lienzo de Jucutacato (1565), elaborado por nahuas michoacanos, aparezca un gobernante chichimeca uacúsecha que se ajusta a esta descripción (Roskamp, 1998: 11 y Martínez Baracs, 2005: 52-53). En el texto y las pinturas indígenas de la Relación de Michoacán no se menciona esta costumbre para los señores supremos. Únicamente se enfatiza el uso de guirnaldas en la cabeza, hechas de trébol, cuero de venado u ocelote, plumas o incluso de oro (tipo diadema), combinadas con una trenza larga que llegaba hasta la espalda baja: se envolvía el pelo largo con tiras de materiales de distintos colores y texturas, a menudo los mismos que se empleaban para la propia guirnalda (Alcalá, 2000: 526, 600, 649, etc.). El pelo largo con trenza también es la característica distintiva de los chichimecas uacúsecha que aparecen en las pinturas de Carapan y Nahuatzen, pertenecientes al género de los títulos primordiales (Roskamp, 2003: 316, 319; 2004: 294-295, fig. 1).

${ }^{80}$ Este gran banquete también es referido en el llamado Códice de Tzintzuntzan, nombre que se le ha otorgado a las ilustraciones indígenas reproducidas por fray Pablo Beaumont en el siglo xvIII (Roskamp, 1997: 223-224). 
sabían desollar y asar un venado, dejando esta tarea para Tariacuri, sugiriendo que no compartían este elemento clave de la identidad chichimeca. Resulta interesante observar que de acuerdo al título fue más bien al revés: los de Curinguaro acostumbraban comer carne animal pero Tariacuri preparó otro tipo de alimento. Esto implica una contradicción en la narrativa ya que al principio de la misma, como señalamos arriba, se enfatiza precisamente el carácter chichimeca de Zuangua, el supuesto padre de Tariacuri, quien cazaba y comía conejos, venados, culebras y codornices.

Como la sección del título que trataba de la llegada de los españoles se encuentra destruida y los dos trasuntos terminan antes, ni siquiera incluyendo la última parte de la narración sobre los sucesos prehispánicos, resulta imposible realizar una comparación con otras fuentes más antiguas. No obstante, es probable que haya referido a la llegada de los conquistadores, su recepción pacífica en Tzintzuntzan y el inicio de la evangelización, como se narra en la Relación de Michoacán (Alcalá, 2000: 660-691) y el Códice de Tzintzuntzan (Roskamp, 1997: 221-229).

\section{Reflexiones finales}

Como muestra la comparación de su contenido con la Relación de Michoacán, el título primordial en lengua tarasca que recoge la historia de fundación y deslinde de Tócuaro claramente se remite a la tradición histórica de los chichimecas uacúsecha que lograron unir a los pueblos michoacanos en un solo reino por medio de conquistas y alianzas matrimoniales. Su autor desconocido debe haber tenido acceso a narraciones orales y quizá incluso otros documentos escritos (por ejemplo, títulos primordiales de pueblos de la misma comarca) que se referían a las principales hazañas del mencionado linaje. Aunque estas fuentes todavía conservaban diversos elementos claves de la historia, cultura, discursos legitimadores e identidad de los antiguos gobernantes, la información obviamente había experimentado cambios al ser transmitida de generación en generación (en un periodo de casi dos siglos). Al parecer no solo se trata de olvidos y confusiones (de sucesos, fechas, nombres de personas y lugares) sino también de ajustes deliberados para adecuar los contenidos a las nuevas realidades y necesidades de sus usuarios. Cabe agregar que las contradicciones entre ciertos datos encontrados en el discurso antiguo del petamuti (es decir la versión registrada en la Relación de Michoacán) y las narraciones más tardías de los títulos, incluyendo el ejemplar de Tócuaro, no necesariamente implican que estos últimos estén equivocados: tal vez reflexionan sobre los mismos acontecimientos pero desde un ángulo diferente o bien remiten a otros sucesos completamente omitidos por la 
mencionada fuente del siglo xvI. En este sentido siempre se debe tener en cuenta que tampoco la propia Relación de Michoacán, aunque es más extensa y temprana, se escapa de los intereses particulares de los múltiples actores sociales involucrados en su elaboración y de ninguna manera es una historia objetiva del pasado prehispánico de Michoacán. Aun así es un punto de referencia imprescindible para el análisis de narrativas más tardías que forman parte de la misma tradición histórica y cultural que se desarrolló desde antes de la llegada de los españoles y de la redacción del mencionado texto por fray Jerónimo de Alcalá.

La comparación del título en lengua tarasca con los dos trasuntos nos puede llevar a las siguientes reflexiones sobre la posible relación entre ellos. El autor (traductor y escribano) del trasunto de la BNAH omitió la conquista de Pátzcuaro y la llegada de los españoles, pero agregó una descripción de los linderos de Jarácuaro. Al parecer era importante rescatar y enfatizar la información sobre los límites territoriales de Jarácuaro y de Tócuaro. El trasunto termina justo después de la especificación de las mojoneras de este último pueblo, en la sección que resalta el papel del título como testimonio de la verdad para la defensa de las tierras y la conservación de la paz. Es probable que esta versión fuera sacada para algún trámite o litigio relacionado con el territorio local, práctica muy común en la región (Roskamp, 2010). Posteriormente, en circunstancias parecidas, se elaboró el otro trasunto — el publicado por León — que claramente es una copia del primero: muestra algunos errores paleográficos (sobre todo en los topónimos y antropónimos) y una modernización de la ortografía. Llama la atención que en este caso se agregó la fecha 7 de agosto de 1615, dato que no aparece en el título tarasco ni en el primer trasunto y pudo haberse tomado de otra documentación — desconocida por nosotros — que su autor tenía a la mano. Al traducir y copiar textos, no solamente se cometían errores sino que frecuentemente se hacían ajustes deliberados para adecuar los contenidos a los diversos contextos de uso (Roskamp, 2010). En el caso que nos concierne, llama mucho la atención que en los trasuntos se incluyeron las mojoneras de Jarácuaro, información que debe haber venido de otra fuente y que quizá se haya agregado por un conflicto común con alguno de los vecinos de ambos pueblos, posiblemente Pareo. Los tres colindaban y, como vimos, el título resalta un enfrentamiento sobre recursos naturales (leña del cerro) entre este último lugar y Jarácuaro, además de dejar en claro la relación directa entre Jarácuaro y Tócuaro. En este sentido los trasuntos parecerían constituir incluso un título de tierras que podía ser empleado por los dos pueblos. Por ende, a pesar de las claras similitudes en los contenidos, las evidencias disponibles no nos permiten inferir que los trasuntos se basan directamente en el título en lengua tarasca de Tócuaro de la BNAH. Además de modificaciones intencionales, las diferencias detectadas también podrían deberse a la 
existencia de otras versiones del título, inclusive en lengua indígena, que sirvieron como fuente y que ahora se encuentran perdidas (destruidas o todavía no localizadas). Por el momento únicamente podemos concluir que los documentos disponibles están relacionados entre sí y remiten, con sus variaciones, a una misma narración básica.

Al haber logrado la traducción del título primordial en lengua tarasca de Tócuaro, así como el análisis de su contenido y su comparación con los dos trasuntos en lengua española, queda pendiente la identificación de los posibles contextos históricos en que los documentos fueron creados y usados, lo que implica una investigación de la historia agraria desde la Colonia temprana hasta nuestros días, no solamente en Tócuaro sino también en Jarácuaro y los pueblos vecinos de ambos. Este tema, sobre el cuál ya se dispone de diversos avances, tendrá que ser abordado en una publicación posterior.

\section{Abreviaturas}

1SG primera persona nominativo singular

$=1 \mathrm{PL} \quad$ primera persona nominativo plural

$1 / 2 \quad$ primera 0 segunda persona nominativo singular o plural, modo indicativo

1/2PAS primera o segunda persona nominativo singular o plural, tiempo pasado

$=3 \mathrm{PL} \quad$ tercera persona plural, modo indicativo

1/2/3 todas las personas, singular o plural, modo subjuntivo

1/2/3PAS todas las personas, singular o plural, tiempo pasado

$=2 \mathrm{SG} \quad$ segunda persona singular

$=2 \mathrm{PL} \quad$ segunda persona nominativo plural

3 tercera persona singular o plural, modo indicativo

3PAS tercera persona singular o plural en tiempo pasado

$=3 \mathrm{PL} \quad$ tercera persona nominativo plural

$=1 / 3=1 / 2 \quad$ primera 0 tercera persona nominativo singular 0 plural; primera persona acusativo singular o plural; por lo menos una, ya sea la persona con función nominativo o acusativo, es plural

A.CASO acusativo

A.3PL tercera persona plural con función acusativo

A.GRAL acusativo general

AG.GRAL agente general, posee dos funciones, como pasiva impersonal o como agente plural

ACC.IND acción individual, posee varias funciones, como reflexiva o como voz media

ANG.R morfema de espacio nominativo, refiere a un ángulo recto

AUX auxiliar

BENEF.3 benefactivo de tercera persona singular o plural

BENEF.PSV pasivo de benefactivo

CABEZ morfema de espacio nominativo; superficie superior de un cuerpo

CAUS Causativo

COND tiempo condicional

CONS consecutivo, indica acción realizada después de una acción previa por lo que también incluye el frecuentativo 


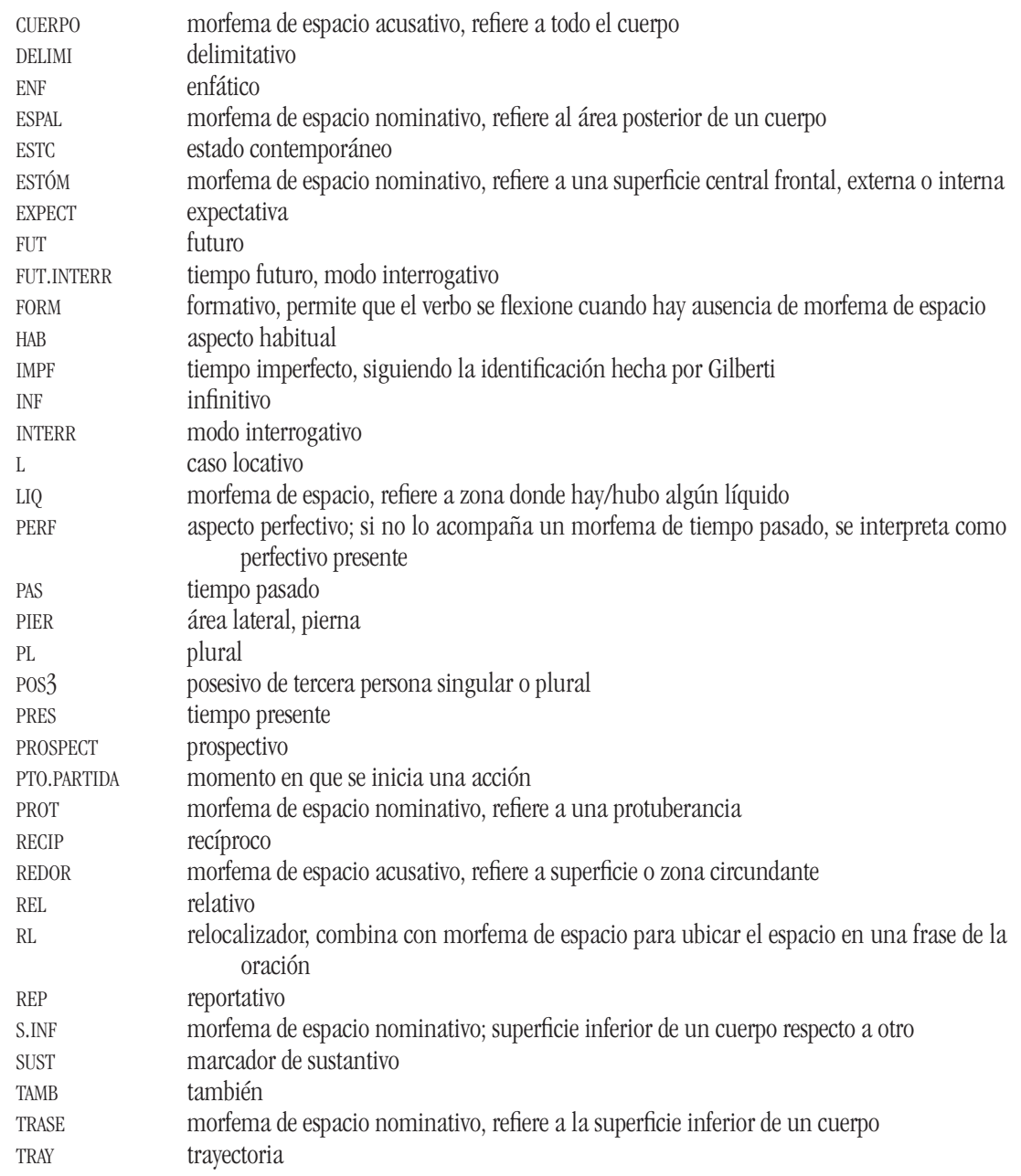

\section{Referencias}

ALCALÁ, Jerónimo de

2000 Relación de las Cerimonias y Rictos y Población y Gobernación de los Indios de la Provincia de Mechuacán [1539-1541]. Zamora: El Colegio de Michoacán, Gobierno del Estado de Michoacán. 
BeLtrán HenríqueZ, Patricia A.

2012 Cosmovisión y Ritual en el Michoacán Prehispánico. México: Universidad Autónoma de Ciudad Juárez.

CarRasco, Pedro

1969 "Nuevos datos sobre los nonoalca de habla mexicana en el reino tarasco", Estudios de Cultura Nábuatl 7: 215-221.

Covarrubias OROzCo, Sebastián de

1995 Tesoro de la Lengua Castella o Española [1611], edición de Felipe C.R. Maldonado revisada por Manuel Camarero. Madrid: Editorial Castalia.

Diccionario grande de la lengua de Michoacán [siglo XvI]

1991 Por autor o autores desconocidos, introducción, paleografía y notas por J. Benedict Warren, 2 volúmenes. Morelia: Fímax Publicistas.

ESPEjEL, Claudia

2008 La Justicia y el Fuego: Dos Claves para Leer la Relación de Michoacán. Zamora: El Colegio de Michoacán.

FAUGÈRE KALFON, Brigitte

1998 "Venados y hogares sagrados en la Relación de Michoacán: reivindicación nórdica y construcción del Estado en los pueblos tarascos", en Génesis, Culturas y Espacios en Michoacán, Véronique Darras, coordinación, pp. 89-99. México: Centro de Estudios Mexicanos y Centro Americanos (CEMCA).

GILBERTI, fray Maturino

1997 Vocabulario en Lengua de Mechuacán [1559], transcripción paleográfica por Agustín Jacinto Zavala, revisión paleográfica por Clotilde Martínez y J. Benedict Warren. Zamora: El Colegio de Michoacán, Fideicomiso Teixidor.

GLASS, John B.

1964 Catálogo de la Colección de Códices. México: Instituto Nacional de Antropología e Historia, Museo Nacional de Antropología.

GLASS, John B., y Donald ROBERTSON

1975 "A Census of Native Middle American Pictorial Manuscripts", en Handbook of Middle American Indians, Guide to Ethnohistorical Sources, Howard F. Cline, editor del volumen, part 3, vol. 14, pp. 81-252. Austin: University of Texas Press.

HeRRejón PEREDO, Carlos

2000 Los Orígenes de Guayangareo-Valladolid. Zamora: El Colegio de Michoacán, Frente de Afirmación Hispanista.

LAGuNAS, fray Juan Baptista de

1983 Arte y Dictionario con otras Obras en Lengua Michuacana [1574]. Morelia: Fimax Publicistas Editores (colección "Fuentes de la Lengua Tarasca o Purépecha" I). 
LEÓN, Nicolás

1906 "Los tarascos. Notas históricas, étnicas y antropológicas. Tercera parte", Anales del Museo Nacional de México, $2^{a}$ época, tomo III: 298-479.

1990 "Códex Plancarte" [1888], Anales del Museo Michoacano, 3 a época, núm. 2: 43-61. Morelia, Instituto Nacional de Antropología e Historia.

LóPEZ CABALLERO, Paula

2003 Los Títulos Primordiales del Centro de México. México: Consejo Nacional para la Cultura y las Artes.

LóPEz SARRELANGUE, Delfina E.

1965 La Nobleza Indígena de Pátzcuaro en la Época Virreinal. México: Universidad Nacional Autónoma de México, Instituto de Investigaciones Históricas.

MARTÍNEZ BARACS, Rodrigo

2005 Convivencia y Utopía: El Gobierno Indio y Español de la 'Ciudad de Mechuacan', 1521-1580. México: Consejo para la Cultura y las Artes, Instituto Nacional de Antropología e Historia, Fondo de Cultura Económica.

MONZÓN, Cristina

2005 "Los principales dioses tarascos: un ensayo de análisis etimológico en la cosmología tarasca”, Relaciones. Estudios de Historia y Sociedad 26 (104): 137-168. Zamora: El Colegio de Michoacán.

2007 "La semilla misionera; una historia de la grafía en documentos de amanuenses tarascos durante el siglo XVI", en Romania en Interacción: Entre Historia, Contacto y Política. Ensayos en Homenaje a Klaus Zimmermann, Martina Schrader-Kniffki y Laura Morgenthaler García, editores, pp. 879-903. Frankfurt/ Madrid: Vervuert/ Iberoamericana.

2013 "Título de Cherán Hatzicurin", en Artes, Vocabularios, Doctrinas y Confesionarios en Lenguas de México, Andrés Acosta Félix, Zarina Estrada Fernández y Aarón Grageda Bustamante, editores, pp. 47-71. Hermosillo: Universidad de Sonora.

2018 Arte de la Lengua de Michuacan Compilada por fray Maturino Gylberti. Transcripción, edición y notas de Cristina Monzón. Zamora: El Colegio de Michoacán, Fideicomiso Felipe Teixidor y Monserrati Alfau Teixidor.

Monzón, Cristina, Hans Roskamp, y J. Benedict Warren

2009 "La memoria de don Melchor Caltzin (1543): historia y legitimación en Tzintzuntzan, Michoacán", Estudios de Historia Novobispana 40: 21-55.

NAVARRETE, Federico

2011 "Chichimecas y toltecas en el Valle de México", Estudios de Cultura Nábuatl 42: $19-50$. 
OUDIJK, Michel

2000 Historiography of the Bènizàa: The Postclassic and Early Colonial Periods (1000-1600 A.D.). Leiden: Researchschool CNWS, Leiden University (CNWS Publications vol. 84).

RoskamP, Hans

1997 "Pablo Beaumont and the Codex of Tzintzuntzan; a Pictorial Document from Michoacan, West Mexico", en Códices, Caciques y Comunidades, Maarten Jansen, Luis Reyes y Raymond Buve, editores, pp. 193-245. Ridderkerk: Asociación de Historiadores Latinoamericanistas Europeos (Cuadernos de Historia Latinoamericana, núm. 5).

1998 La Historiografía Indígena de Michoacán: El Lienzo de Jucutácato y los Títulos de Carapan. Leiden: Researchschool CNWS, Leiden University (CNWS Publications vol. 72).

2000 "El carari indígena y las láminas de la Relación de Michoacán: un acercamiento", en La Relación de Michoacán, Moisés Franco Mendoza, coordinador, pp. 235-264. Zamora: El Colegio de Michoacán, Gobierno del Estado de Michoacán.

2002 "La heráldica novohispana del siglo XVI: un escudo de armas de Tzintzuntzan, Michoacán”, en Esplendor y Ocaso de la Cultura Simbólica, Herón Pérez Martínez y Bárbara Skinfill Nogal, coordinadores, pp. 227-268. Zamora: El Colegio de Michoacán, CONACYT.

2003 "Los 'Títulos Primordiales’ de Carapan, Michoacán: legitimación en una comunidad indígena", en Autoridad y Gobierno Indígena en Michoacán: Ensayos a través de su Historia, Carlos Paredes Martínez y Martha Terán, coordinadores, pp. 305-360. México: El Colegio de Michoacán, CIESAS, INAH-Dirección de Estudios Históricos, UMSNH-Instituto de Investigaciones Históricas.

2004 "El Lienzo de Nahuatzen: origen y territorio de una comunidad de la sierra tarasca, Michoacán”, Relaciones. Estudios de Historia y Sociedad XXV (100): 279-313. Zamora: El Colegio de Michoacán.

2010 "Memoria, identidad y legitimación en los Títulos Primordiales de la región tarasca", en Caras y Máscaras de México Étnico. Las Formaciones del Estado Mexicano, Andrew Roth Seneff, editor, vol. I, pp. 39-53. Zamora: El Colegio de Michoacán.

2011a "El mapa de Santa Fe de la Laguna, Michoacán: la defensa territorial de un pueblohospital a mediados del siglo XVI", en Patrones de Asentamiento y Actividades de Subsistencia en el Occidente de México: Reconocimiento a la Dra. Helen Perlstein Pollard, Eduardo Williams y Phil Weigand, editores, pp. 141-170. Zamora: El Colegio de Michoacán. 
2011b "Las intrigas del gobernador tarasco don Pedro Cuiniharangari", Arqueología Mexicana XIX (112): 42-47.

2012 "Memories of a Kingdom: the Tarascan and Nahua Foundation of Prehispanic Tzintzuntzan, West-Mexico", en Mesoamerican Memory: Enduring Systems of Remembrance, Amos Megged y Stephanie Wood, editores, pp. 113-127. Oklahoma: University of Oklahoma Press.

2013 "El escudo de los tres reyes de Tzintzuntzan: iconografía, memoria y legitimación en la antigua capital tarasca", en Los Escudos de Armas Indígenas: De la Época Colonial al México Independiente, María Castañeda de la Paz y Hans Roskamp, editores, pp. 137-168. Zamora: El Colegio de Michoacán, Universidad Nacional Autónoma de México.

2015 "Visions of the Past: The Tarascan Kingdom and the Late Colonial Primordial Titles from Michoacán", en From Tribute to Communal Sovereignty. The Tarascan and Caxcan Territories in Transition, Andrew Roth Seneff, Robert V. Kemper y Julie Atkins, editores, pp. 113-132. Tucson: University of Arizona Press.

2016 “Conquista y evangelización en los Títulos Primordiales de Michoacán”, en Los Códices Mesoamericanos: Registros de Religión, Política y Sociedad, Miguel Ángel Ruz Barrio y Juan José Batalla Rosado, coordinadores, pp. 311-342. Toluca: El Colegio Mexiquense.

SCHULTZE-BERNDT, Eva

2007 "La anotación lingüística", en Bases de la Documentación Lingüística, John B. Haviland y José Antonio Flores Farfán, coordinadores de la versión en español, pp. 251-295. México: INALI.

STONE, Cynthia L.

2004 In Place of Gods and Kings: Authorship and Identity in the Relación de Michoacán. Oklahoma: Oklahoma University Press.

Velásquez GaLlardo, Pablo

1952 “Título de tierras de Cherán Hatzicurin”, Tlalocan 3: 238-245.

WARREN, J. Benedict

1985 The Conquest of Michoacán. The Spanish Domination of the Tarascan Kingdom in Western Mexico, 1521-1530. Norman: University of Oklahoma Press.

1989 La Conquista de Michoacán 1521-1530. Morelia: Fimax (Colección Estudios Michoacanos VI). 


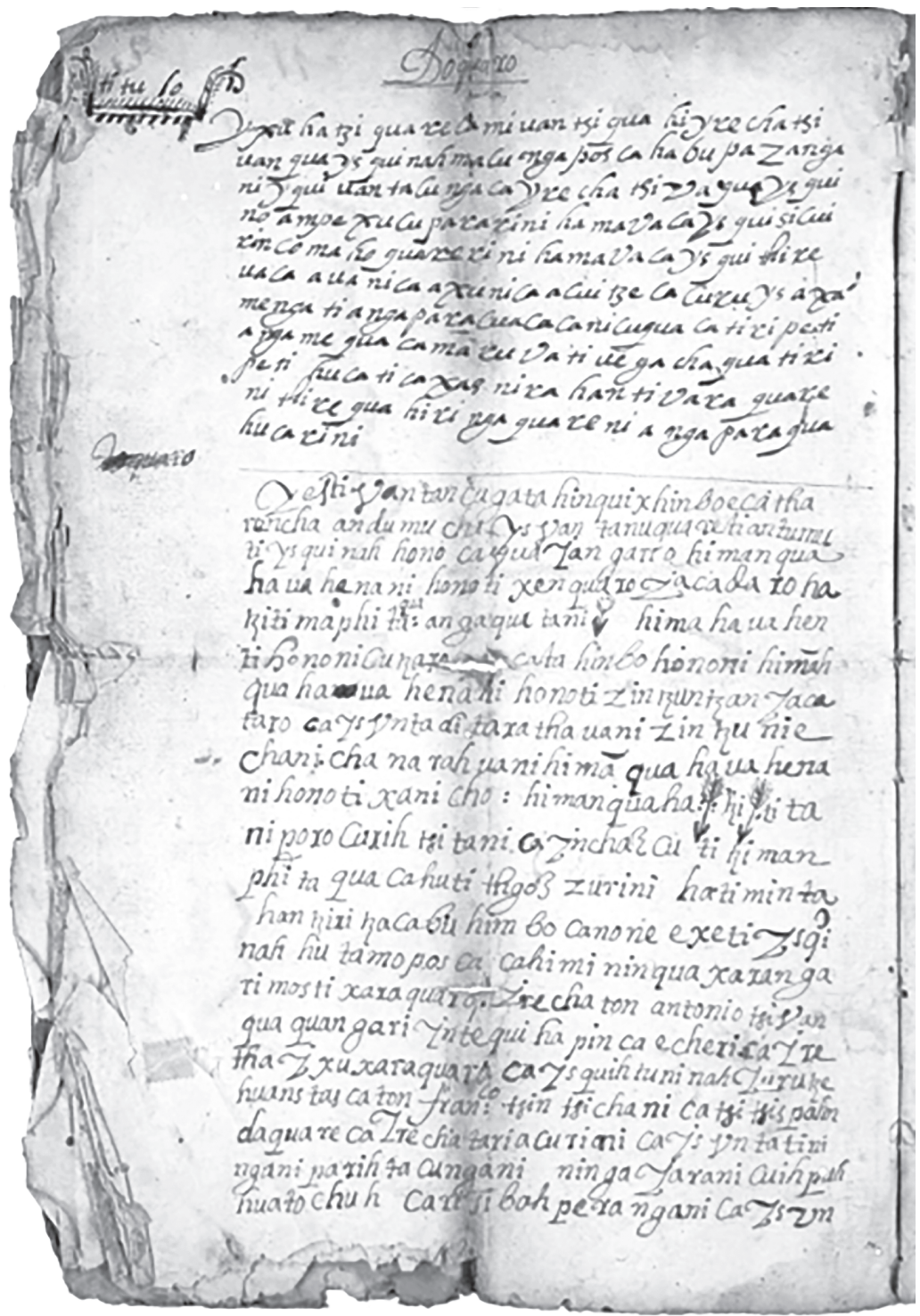

Figura 1. "Títulos de Tócuaro"

Reproducción autorizada por el Instituto Nacional de Antropología e Historia. Secretaría de Cultura, INAH, México, Biblioteca Nacional de Antropología e Historia (INAH), clave 35-116, foja $11 \mathrm{v}$ 


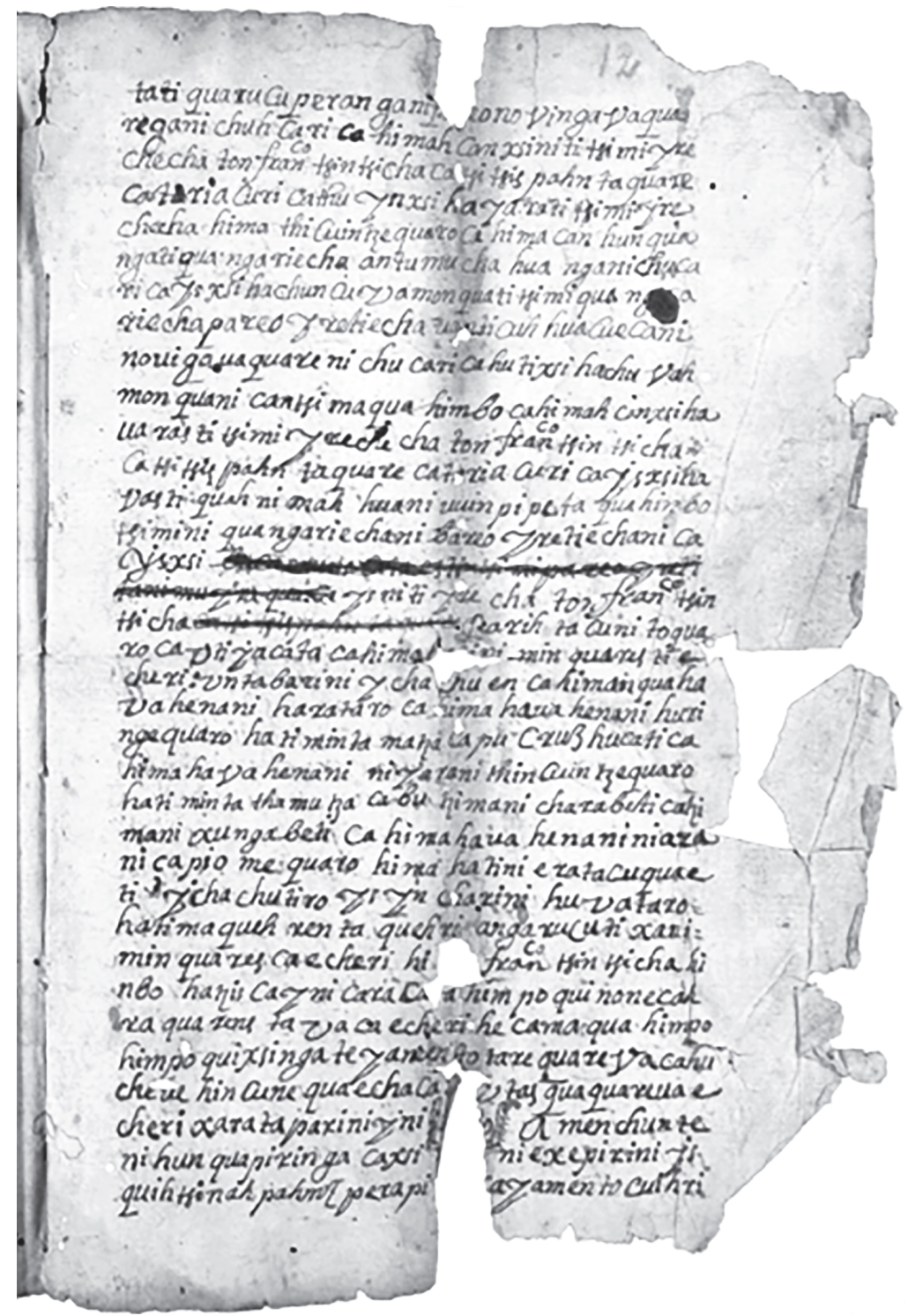

Figura 2. "Títulos de Tócuaro"

Reproducción autorizada por el Instituto Nacional de Antropología e Historia. Secretaría de Cultura, INAH, México, Biblioteca Nacional de Antropología e Historia (INAH), clave 35-116, foja $12 \mathrm{r}$ 


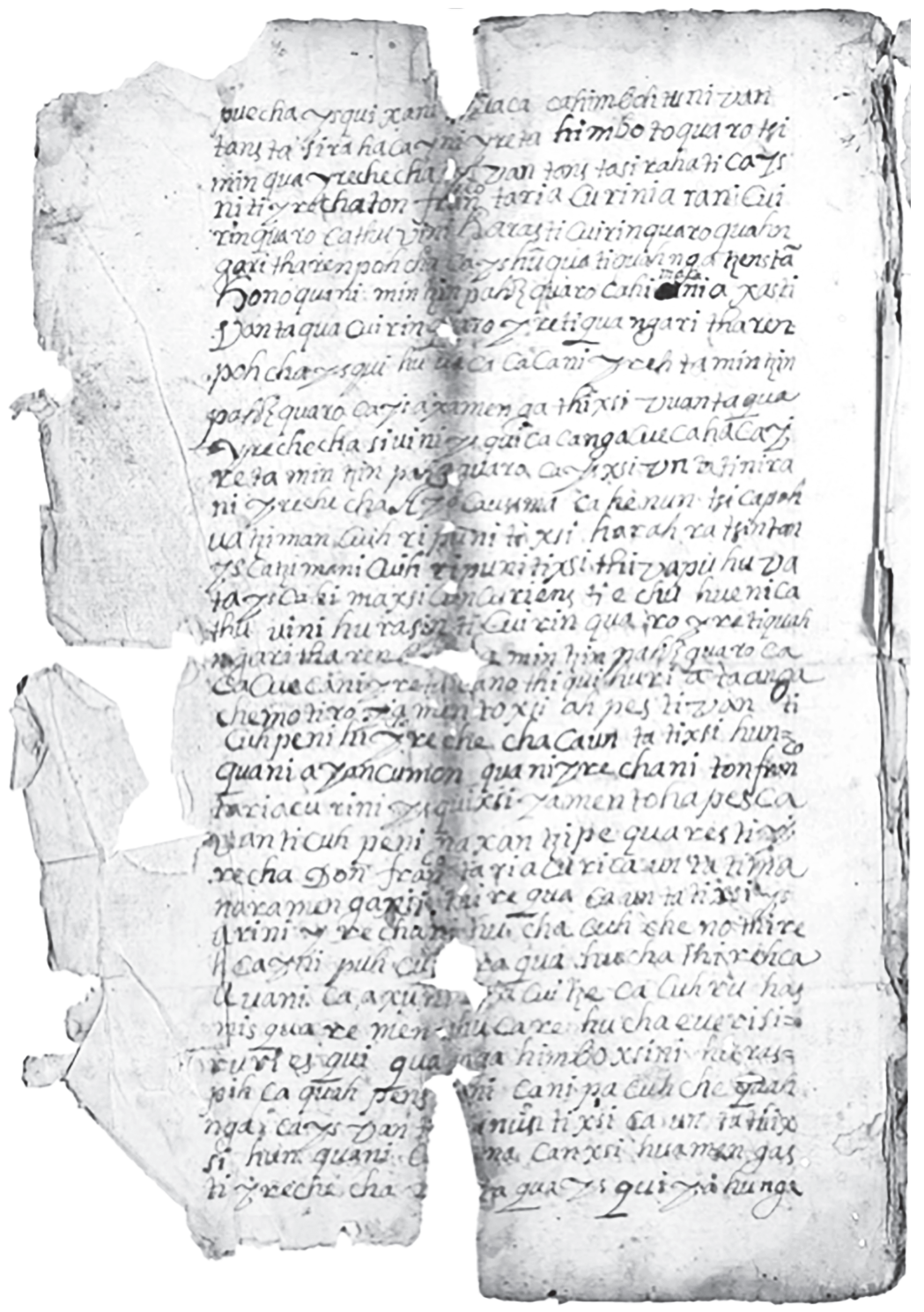

Figura 3. "Títulos de Tócuaro"

Reproducción autorizada por el Instituto Nacional de Antropología e Historia. Secretaría de Cultura, INAH, México, Biblioteca Nacional de Antropología e Historia (INAH), clave 35-116, foja $12 \mathrm{v}$ 


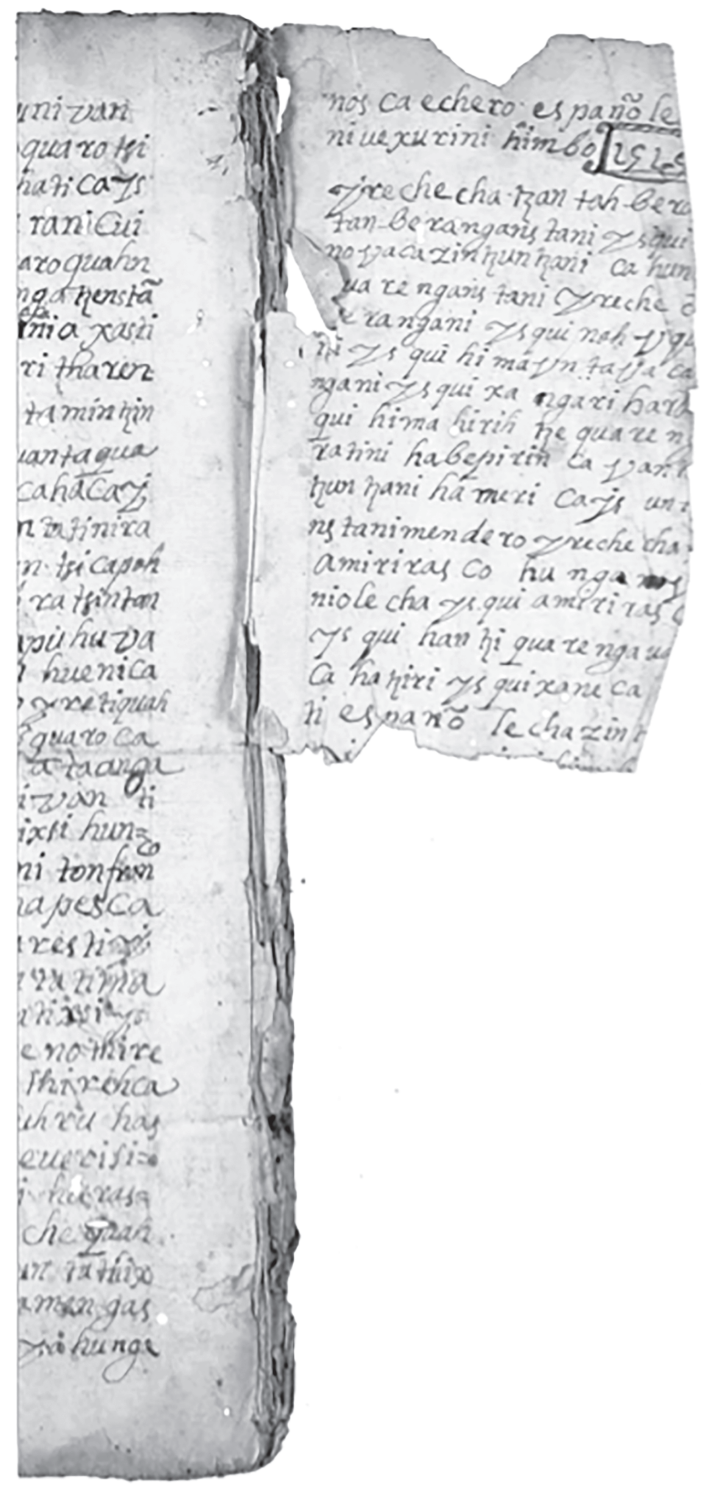

Figura 4. "Títulos de Tócuaro"

Reproducción autorizada por el Instituto Nacional de Antropología e Historia. Secretaría de Cultura, INAH, México, Biblioteca Nacional de Antropología e Historia (INAH), clave 35-116, foja 13r (con margen derecho de la foja 12v) 
Tabla 2. La traducción del título tarasco de Tócuaro (Monzón y Roskamp)

y los dos trasuntos (BNAH y León)

\begin{tabular}{|c|c|c|}
\hline $\begin{array}{c}\text { Traducción (Monzón y } \\
\text { Roskamp) }\end{array}$ & Trasunto (T-BNAH) & $\begin{array}{l}\text { Trasunto (T-NL, León } \\
\text { 1906: 405-406) }\end{array}$ \\
\hline $\begin{array}{l}\text { [f.11v] (1) Aquí yo, el rey } \\
\text { Tsiuangua, de mi voluntad he } \\
\text { puesto mi memoria sobre cómo } \\
\text { en distintos lugares los parientes } \\
\text { lo guardan en su pecho. }\end{array}$ & $\begin{array}{l}\text { [f.9r.] Aqui Pongo yo } \\
\text { el Rey tziVangua memoria } \\
\text { de como }[\mathrm{ar}] / \text { maron Rey i } \\
\text { como abia de andar i de que } \\
\text { abia de bestir. }\end{array}$ & $\begin{array}{l}\text { [p.405] Aqui pongo yo el } \\
\text { Rey TziUangua, me armaron } \\
\text { Rey, y como habia de andar y } \\
\text { de que habia de vestir: }\end{array}$ \\
\hline $\begin{array}{l}\text { (2) Entonces se le pidió al } \\
\text { rey Tsiuangua que no se vistiese, } \\
\text { que fuese únicamente un cuero } \\
\text { lo que se amarrase [y] que co- } \\
\text { miese conejos, venados, cule- } \\
\text { bras y codornices. }\end{array}$ & $\begin{array}{l}\text { Y/ que no auia de andar } \\
\text { bestido cino es faxado con } \\
\text { un quero. i q[ue]/ auia de } \\
\text { comer conejos benados co- } \\
\text { dorniçes i culebras. }\end{array}$ & $\begin{array}{l}\text { lo que no habia de andar } \\
\text { vestido sino es forrado con } \\
\text { un cuero y que habia de co- } \\
\text { mer conejos, venados, godor- } \\
\text { nices y culebras }\end{array}$ \\
\hline $\begin{array}{l}\text { (3) Así se le envió un carcaj } \\
\text { de flechas y un arco. Y él tenía } \\
\text { puesto un bezote de oro y un } \\
\text { collar de oro precioso. Y de este } \\
\text { modo él iba a cazar, era comida } \\
\text { la que buscaba con el carcaj de } \\
\text { flechas. }\end{array}$ & $\begin{array}{l}\text { i com }[0] / \text { me imbiaron } \\
\text { un carcaje de flechas, i un } \\
\text { arco, i una mascara [de]/ } \\
\text { oro. i una gargantilla de oro } \\
\text { i asi iba a buscar en persona } \\
\text { a [sa]/car que comer con su } \\
\text { arco i flecas.- }\end{array}$ & $\begin{array}{l}\text { y como me inviaron un } \\
\text { carcax de flechas y un arco, } \\
\text { y un mascarin oro, y una } \\
\text { gargantilla de oro, y asi iba á } \\
\text { vuscar en persona, Aran, que } \\
\text { comer con su arco y flechas. }\end{array}$ \\
\hline $\begin{array}{l}\text { (4) Esta es la ley por la que } \\
\text { los ancianos son honorables, tal } \\
\text { como el honorable hizo el tes- } \\
\text { tamento. }\end{array}$ & $\begin{array}{l}\text { esto es tambien el man- } \\
\text { dato q[ue]/ los balientes dio, } \\
\text { andubieçen de la misma ca- } \\
\text { lidad. }\end{array}$ & $\begin{array}{l}\text { Este es tambien el man- } \\
\text { dato que los valientes dio, } \\
\text { anduviesen de la misma ca- } \\
\text { lidad. }\end{array}$ \\
\hline $\begin{array}{l}\text { (5) Cómo [Tsiuangua] } \\
\text { decidió llegar a Guayangareo. } \\
\text { Luego salió de ahí y llegó a Xen- }\end{array}$ & $\begin{array}{l}\text { tambie[n]/ salio de bal- } \\
\text { ladolid. Y fue al pueblo de } \\
\text { capula i paro en un edifi- }\end{array}$ & $\begin{array}{l}\text { Tambien salio Guayán- } \\
\text { gareo y fue al pueblo de Ca- } \\
\text { pula y paró en un edificio y }\end{array}$ \\
\hline
\end{tabular}




\begin{tabular}{|c|c|c|}
\hline $\begin{array}{l}\text { guaro, al costado de las yácatas } \\
\text { clavó una flecha. De allí salió y } \\
\text { llegó a Cutzare, llegó a las yá- } \\
\text { catas. Luego de ahí partió [y] } \\
\text { llegó a las yácatas de Tzintzunt- } \\
\text { zan y así hizo que los colibríes } \\
\text { empezasen a volar, los hizo ju- } \\
\text { gar. Luego salió de ahí [y] llegó } \\
\text { a Xanicho, [donde] entonces } \\
\text { puso en tres lugares que emitían } \\
\text { llamaradas y clavó en el suelo } \\
\text { dos flechas. Al irse se tropezó, } \\
\text { hay una piedra con una huella } \\
\text { por señal y nadie la vio puesto } \\
\text { que venían pasando por varios } \\
\text { lugares. }\end{array}$ & $\begin{array}{l}\text { [cio]/ i ahi paro una flecha, } \\
\text { de all salio para el puesto de } \\
\text { cutzaro, i pa[ro en]/ el edi- } \\
\text { ficio i alli enpeso a echar a } \\
\text { bolar pajaros por su mano. } \\
\text { de alli/ i fue al pueblo de } \\
\text { xanicho, i alli puso tres } \\
\text { rraias i clabo dos flechas/ i } \\
\text { salto sobre una loss[...] alli } \\
\text { ceñalados los pies i no bido } \\
\text { ninguna/ passo }\end{array}$ & $\begin{array}{l}\text { allí paró una flecha, de alli } \\
\text { salio para el puesto de Cutza- } \\
\text { ro y pasó el edificio y alli em- } \\
\text { pesó á hechar á volar pajaros } \\
\text { por su mano; de alli y fué al } \\
\text { pueblo de Janicho y alli puso } \\
\text { tres zzacas y clavó dos flechas } \\
\text { y salto sobre una losa y dejó } \\
\text { alli señalados los pies y no } \\
\text { vido ninguno el paso, }\end{array}$ \\
\hline $\begin{array}{l}\text { (6) Y se dice que de regreso } \\
\text { el rey don Antonio Tsiuangua se } \\
\text { mostró en Xaraquaro, el valien- } \\
\text { te que tiene la tierra y el pueblo } \\
\text { aquí en Xaraquaro. Y entonces } \\
\text { él también engendró a Francis- } \\
\text { co Tsintsicha, a Tsitsipandaqua- } \\
\text { re y al rey Tariacuri. }\end{array}$ & $\begin{array}{l}\text { i de alli columbro a xa- } \\
\text { raquaro el Rey D. Antonio } \\
\text { tziVang[..]/ el baliente dueño } \\
\text { de este pueblo i tierras, i des- } \\
\text { de el edificio tiro su/ flecha i } \\
\text { fue a dar al puesto de thin- } \\
\text { guintzequaro, ceñalando asi } \\
\text { sus/ tierras. tiro otra flecha al } \\
\text { puesto donde dejo señalados } \\
\text { los pies en la [...]/ tiro otra } \\
\text { flecha haçea el puesto de na- } \\
\text { pilo donde esta un cerrillo i } \\
\text { ab[ia]/ una piedra grande la } \\
\text { qual tiene por çeñal una fle- } \\
\text { cha, i tiro otra [que]/ fue a } \\
\text { dar al pie de un cerrillo don- } \\
\text { de esta un monton de pie- } \\
\text { dras. todas est[as]/ tierras }\end{array}$ & $\begin{array}{l}\text { y de alli columbró á Ja- } \\
\text { rácuaro el Rey Dn. Antonio } \\
\text { TziUangua el valiente dueño } \\
\text { de este pue[p.406]blo y tie- } \\
\text { rra y desde el edificio tiró una } \\
\text { flecha y fué á dar al puesto } \\
\text { de Ahinga entrecuaro, seña- } \\
\text { lando asi sus tierras, tiró otra } \\
\text { flecha al puesto donde dejó } \\
\text { señalados los pies en la, tiro } \\
\text { otra flecha hacia el puesto de } \\
\text { Napijo donde está un cerrillo } \\
\text { y abajo una piedra grande la } \\
\text { cual tiene por señal una fle- } \\
\text { cha, y tiró otra fué á dar al } \\
\text { pie de un cerrillo un monton } \\
\text { de piedras todas estas tierras } \\
\text { se separó el TziUangua y por }\end{array}$ \\
\hline
\end{tabular}




\begin{tabular}{|c|c|c|}
\hline & $\begin{array}{l}\text { çe çeparo el Rey tziVangua } \\
\text { i por esso hisso este escrito } \\
\text { que[..]/ ba de titulo=, y de } \\
\text { como tubo tres hijos el uno } \\
\text { llamado D. Francisco tzint- } \\
\text { zich[a]/ i el otro tzitzisphan- } \\
\text { daquare, el otro tariacuri, }\end{array}$ & $\begin{array}{l}\text { eso hiso este escrito que sirva } \\
\text { de titulo y de como tuvo tres } \\
\text { hijos el uno llamado Dn. } \\
\text { Francisco Tzintzicha y el otro } \\
\text { Tzitris jopandaguare, el otro } \\
\text { Tariacari }\end{array}$ \\
\hline $\begin{array}{l}\text { (7) Y así [los reyes] empe- } \\
\text { zaron a ir, iban remando [y] } \\
\text { llegaron al cerro del panal de } \\
\text { árbol. Robaron leña. [f.12r] } \\
\text { Y así empezaron a hacer que } \\
\text { les atajasen el paso [...] les ne- } \\
\text { gaban la leña. Y entonces esos } \\
\text { reyes, don Francisco Tsintsicha } \\
\text { y Tsitsispantaquare y Tariacuri, } \\
\text { se fueron. Y también estos reyes } \\
\text { se quedaron allá en Thicuintze- } \\
\text { quaro. Y entonces los honora- } \\
\text { bles valientes regresaron, traje- } \\
\text { ron la leña. }\end{array}$ & $\begin{array}{l}\text { i estos tres pasaron [en] } \\
\text { canoa i çe desembarcaron } \\
\text { para el monte que llaman } \\
\text { de el pan[..]/ a hurtar leñas, } \\
\text { estos que la fueron a hurtar } \\
\text { eran aquellos balientes [..]/ } \\
\text { estos tres rreies tenian en su } \\
\text { compania, i salieron a la } \\
\text { defen[sa]/ de este monte i de } \\
\text { la leña que llebaban, los ot- } \\
\text { ros balientes [que]/ estaban } \\
\text { en el pueblo [..........]ieron } \\
\text { los rreies/ [f.9v.] tzintzicha. } \\
\text { i tzitzis phandaquare, i ta- } \\
\text { riacuri los tres ermanos/ i } \\
\text { pararon en el puesto donde } \\
\text { llaman thinguintzequaro i } \\
\text { entonses/ llegaron los balie- } \\
\text { ntes con la leña, }\end{array}$ & $\begin{array}{l}\text { y estos tres pasaron por } \\
\text { canoa y se desembarcaron } \\
\text { para el monte que llaman } \\
\text { del panal á juntar leña, y } \\
\text { estos que la fueron á juntar } \\
\text { eran aquellos valientes que } \\
\text { estos tres reyes tenian en su } \\
\text { compañía y salieron á la } \\
\text { defensa de este monte y de la } \\
\text { leña que llevavan, los otros } \\
\text { valientes que estavan en el } \\
\text { pueblo de Pareo á esto vinie- } \\
\text { ron los reyes Dn. Francisco } \\
\text { Tzintzicha y Tzitris jopanda- } \\
\text { cuare, Tariacuri los tres her- } \\
\text { manos y pasaron en el puesto } \\
\text { donde llaman Huinguintze- } \\
\text { quaro y entonces llegaron los } \\
\text { valientes con la leña }\end{array}$ \\
\hline $\begin{array}{l}\text { (8) Y así los valientes ha- } \\
\text { bitantes de Pareo los seguían } \\
\text { de regreso y en un tramo los } \\
\text { quisieron matar, les negaron la } \\
\text { leña. Los siguieron de regreso } \\
\text { en balsas de rama. Y entonces } \\
\text { los reyes don Francisco Tsint- }\end{array}$ & $\begin{array}{l}\text { i tras ellos los otros balie- } \\
\text { ntes/ de pareo defensores de } \\
\text { el monte i leña a querellos } \\
\text { matar/ i entonçes çe amoti- } \\
\text { naron los dichos Reies tres } \\
\text { ermanos i con hon/das co- } \\
\text { mensaron a tirarles a los ba- }\end{array}$ & $\begin{array}{l}\text { y tras ellos los otros va- } \\
\text { lientes de Pareo defensores } \\
\text { del monte y leña á quererlos } \\
\text { matar. Y entonces se amo- } \\
\text { tinaron los dichos Reyes } \\
\text { tres hermanos y con jondas } \\
\text { comenzaron á tirarles á los }\end{array}$ \\
\hline
\end{tabular}




\begin{tabular}{|c|c|c|}
\hline $\begin{array}{l}\text { sicha y Tsitsispahndaquare y Ta- } \\
\text { riacuri, tuvieron que levantarse. } \\
\text { Y así ellos se levantaron, a esos } \\
\text { valientes habitantes de Pareo en } \\
\text { el agua les tiraron con onda. Y } \\
\text { así ellos }\end{array}$ & $\begin{array}{l}\text { lientes defensores de la leña/ } \\
\text { los mataron, }\end{array}$ & $\begin{array}{l}\text { valientes defensores de la } \\
\text { leña y los mataron, }\end{array}$ \\
\hline $\begin{array}{l}\text { (9) esclaros son ellos tres } \\
\text { habitantes subyugados de Pa= } \\
\text { reo y }\end{array}$ & $\begin{array}{l}\text { por lo qual no que- } \\
\text { daron en dicho pueblo de } \\
\text { pareo mas de dos/ personas. }\end{array}$ & $\begin{array}{l}\text { por lo cual no quedaron } \\
\text { en dicho pueblo de Pareo } \\
\text { más de tres personas, }\end{array}$ \\
\hline $\begin{array}{l}\text { (10) así se fue el rey don } \\
\text { Francisco Tsintsicha tsitsi- } \\
\text { a Toquaro y construyó una yá- } \\
\text { cata. Y allá tomó dominio de la } \\
\text { tierra. }\end{array}$ & $\begin{array}{l}\text { despues de esto ce em- } \\
\text { barco D. Francisco tzint- } \\
\text { zicha i fue al pue/blo de } \\
\text { toquaro donde hisso un } \\
\text { edificio donde abito i des- } \\
\text { de este lugar çe/ñalo las } \\
\text { tierras que nececitaba, }\end{array}$ & $\begin{array}{l}\text { despues de esto se embar- } \\
\text { có Dn. Francisco Tzintzicha } \\
\text { y fué al Pueblo de Tócuaro } \\
\text { donde hiso un edificio donde } \\
\text { abitó y desde este lugar seña- } \\
\text { ló las tierras que necesitaba }\end{array}$ \\
\hline $\begin{array}{l}\text { (11) Comenzó en Ycha- } \\
\text { chuen. Y luego se fue a Arataro. } \\
\text { Y de allá se fue a Huringuequa- } \\
\text { ro [donde] hay como señal una } \\
\text { piedra que tiene una cruz. Y de } \\
\text { allá partió para llegar a Thin- } \\
\text { cuintzequaro [donde] hay una } \\
\text { señal de cuatro piedras, dos ro- } \\
\text { jas y dos verdes. Y de allá partió } \\
\text { para llegar a una isla pequeña, } \\
\text { allá hay un mojón, está en la } \\
\text { parte baja de un lugar alarga- } \\
\text { do, así en lo profundo del cerro } \\
\text { [donde] hay un peñasco grande } \\
\text { [que] se yergue en la orilla. }\end{array}$ & $\begin{array}{l}\text { i fue la primera } \\
\text { ichahchuen, i de/ alli al Joio, } \\
\text { i de alli al temascal, don- } \\
\text { de esta Vna piedra grande } \\
\text { qu[e]/ tiene por señal Vna } \\
\text { cruz. i de alli fue al puesto de } \\
\text { thinguint[z]/quaro, donde } \\
\text { dexo por ceñal quatro pie- } \\
\text { dras descoloradas i dos a[..]/ } \\
\text { les rrenegridas, de alli fue } \\
\text { al puesto que llaman çapio- } \\
\text { mequaro que e[s]/ una islita } \\
\text { pequeña. i a la entrada de } \\
\text { el monte en el camino esta } \\
\text { una/ piedra grande. }\end{array}$ & $\begin{array}{l}\text { y fue la primera ichal- } \\
\text { chuen, y de alli al Joro y de } \\
\text { alli al temascal, donde está } \\
\text { una piedra grande que tiene } \\
\text { por señal una cruz y de alli } \\
\text { fue al puesto de Tinguentze- } \\
\text { quaro donde dejó por señal } \\
\text { cuatro piedras, dos coloradas } \\
\text { y dos azules renegridas, de } \\
\text { alli fué al puesto que llaman } \\
\text { Sapocomecuaro que es una } \\
\text { islita pequeña y á la entrada } \\
\text { de el monte en el camino } \\
\text { está una piedra grande. }\end{array}$ \\
\hline
\end{tabular}




\begin{tabular}{|c|c|c|}
\hline $\begin{array}{l}\text { (12) Tanto así yo, don Fran- } \\
\text { cisco Tsintsicha, tengo dominio } \\
\text { sobre la tierra por eso yo este } \\
\text { escrito lo hice para que nadie } \\
\text { escriba mentiras sobre la tierra, } \\
\text { para que todos ellos, pobrecillos, } \\
\text { las labren conmigo. ¿Y siempre } \\
\text { protegerán la tierra? Se ha veni- } \\
\text { do mostrando esta [...] }\end{array}$ & $\begin{array}{l}\text { todas estas tierras des- } \\
\text { de ichahchutiro hasta esta/ } \\
\text { Piedra çe çeparo el dicho } \\
\text { D. Francisco tzintzicha, Rey } \\
\text { de el pueblo de t[o]/quaro } \\
\text { i hisso este escrito para que } \\
\text { en todo tiempo paresca çer } \\
\text { be[r]/dad lo rreferido. }\end{array}$ & $\begin{array}{l}\text { Todas estas tierras desde } \\
\text { Ichahchutiro hasta esta Pie- } \\
\text { dra se separó el dicho Dn. } \\
\text { Francisco Tzintzicha Rey del } \\
\text { pueblo de Tócuaro i hizo } \\
\text { este escrito para que en todo } \\
\text { tiempo paresca ser verdad lo } \\
\text { referido. }\end{array}$ \\
\hline $\begin{array}{l}\text { (13) Si regresase una vez y } \\
\text { ellos viesen [...] cómo ustedes, } \\
\text { todas las personas, se aman los } \\
\text { unos a los otros, }[f .12 v] \text { que } \\
\text { tanto así [...] y por eso tam- } \\
\text { bién sobre este pueblo acostum- } \\
\text { bro hablar porque dicen que en } \\
\text { Tocuaro los reyes así acostum- } \\
\text { bran hablar. }\end{array}$ & $\begin{array}{l}\text { y para que persona nin- } \\
\text { guna pueda decir so/suiar } \\
\text { hiçe este titulo para que çe } \\
\text { defiendan mis ermanos i pa- } \\
\text { rient[es]/ monstrando dicho } \\
\text { titulo. i ce amen i tengan paz } \\
\text { todo esto hago en defen[sa]/ } \\
\text { de mi pueblo llamado to- } \\
\text { quaro }\end{array}$ & $\begin{array}{l}\text { Y para que persona nin- } \\
\text { guna pueda decir son mias } \\
\text { hice este titulo para que se } \\
\text { defiendan mis hermanos y } \\
\text { parientes, mostrando dicho } \\
\text { titulo y se amen y tengan por } \\
\text { todo esto hago en defensa de } \\
\text { mi pueblo llamado Tócuaro. } \\
7 \text { de Agosto de } 1615 \text {. }\end{array}$ \\
\hline $\begin{array}{l}\text { [la versión en lengua ta- } \\
\text { rasca continua en los folios } \\
12 v \text { y } 13 r \text { con las oraciones } \\
14-20]\end{array}$ & [termina el trasunto] & [termina el trasunto] \\
\hline
\end{tabular}




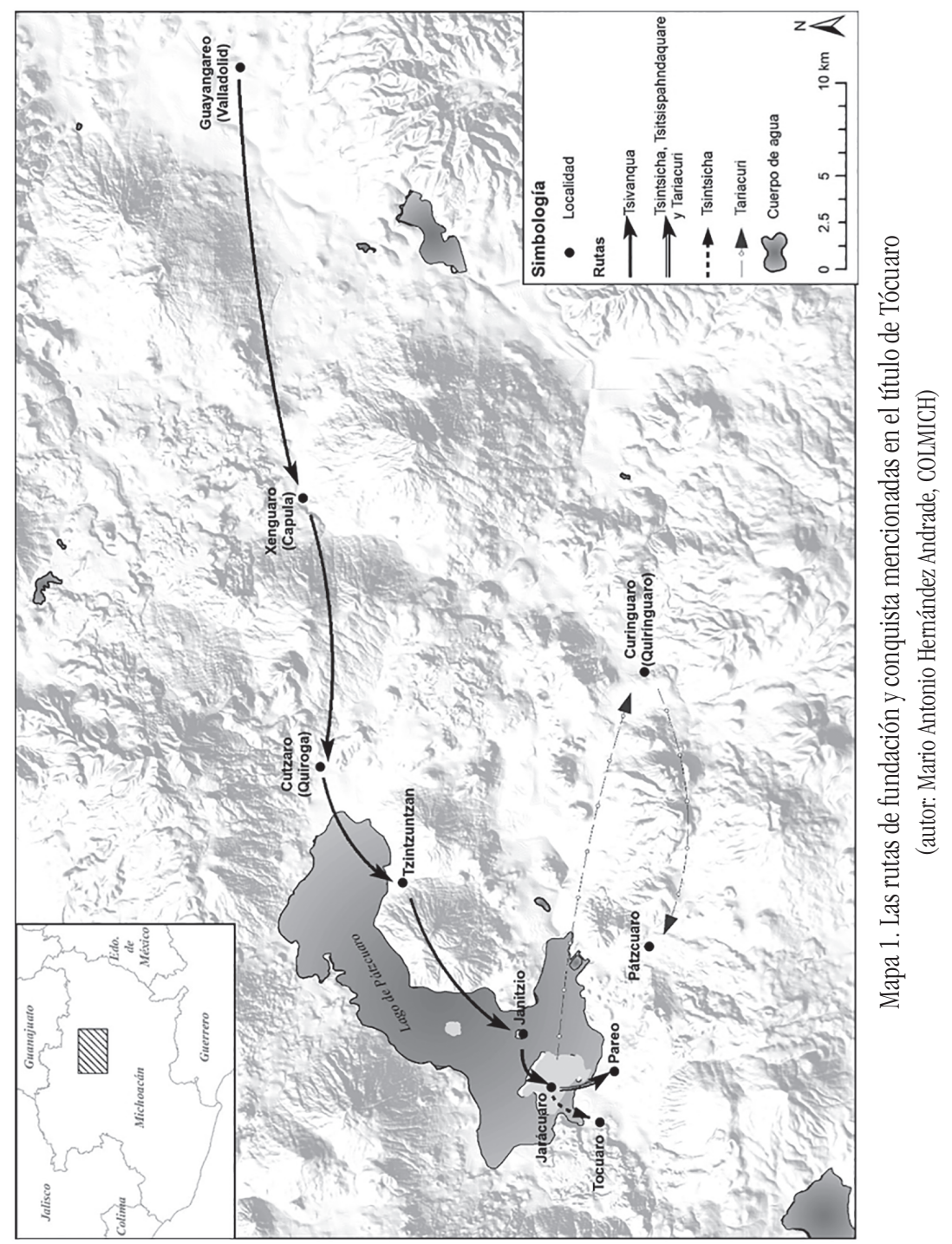


